\title{
THE DELAYED HISTOLOGICAL CHANGES OF SEGMENTAL ISCHEMIA AND ISCHEMIA - REPERFUSION ON THE JEJUNAL VILII OF RABBITS
}

\author{
Shahira Youssef \\ Anatomy Department, Faculty of Medicine, Ain Shams University
}

\section{INTRODUCTION}

Acute intestinal ischemia represents a broad spectrum of diseases with various clinical and pathological manifestations. The primary causes of insufficient blood flow to the intestine are diverse and include thromboembolism, neoplasms, vasculitis, abdominal inflammatory conditions, trauma, chemotherapy, radiation and corrosive injury (Rha et al., 2000). Despite of the advances in the pathophysiological, laboratory diagnosis and imaging techniques acute intestinal ischemia is still one of the major etiological causes of multiple organ failure (Schlichting et al., 1995). Ischemia induces continuous distrubance of hepatic microcirculation leading to liver dysfunction (Nakamura et al., 2001). Furthermore, it triggers the development of lung dysfunction (Ito et al., 2003). Ischemia is often associated with mortality rates more than $60 \%$ and thus it represents a major challenging clinical problem (Lock, 2001).

Reviewing the literature re renled that the intestinal mucosa in particular is one of the most sensitive tissues to ischemia and ischemia reperfusion injury in the human body (Ikeda et al., 1998; Kalia et al., 2001). Although the histopathological alterations in the intestinal mucosa after ischemic injury have been extensively described (Puglisi et al., 1995; Takeyoshi et al., 1996; Ikeda et al., 1998) yet most of the previous models of ischemia were achieved by complete occlusion of the superior mesenteric artery which often resulted in shock and early death of the experimental animals, hence rendering it rather difficult to examine the delayed morphological changes in the ischemic intestinal mucosa. Moreover, the intestinal segments distal to ischemia though clinically showed decreased contraction frequency, decreased relaxation responses and altered responses to norepinephrine (Malone and Kanaan 
2001) yet the morphological changes in locations distal to ischemia were not properly investigated.

Recently, the role of modulators particularly nitric oxide has received special attention. It is hypothesized that nitric oxide might be involved in tissue protection and provide partial preservation of intestinal mucosa as the first line of defense following ischemia reperfusion (Kalia et al., 2001). Detection of nitric oxide could be achieved via the estimation of endothelial nitric oxide synthase (NOS) which is a member of a family of enzymes responsible for synthesis of nitric oxide from $L$ arginine and molecular oxygen (Chan et al., 2002).

Accordingly, it was the aim of the current work to illustrate the delayed morphological and morphometric changes following segmental ischemia and ischemia reperfusion produced by selective occlusion of terminal branches of superior mesenteric artery. Moreover an attempt of detection of nitric oxide production was achieved via the estimation of nitric oxide synthase. The changes in both the ischemic segment as well as the segment distal to it were investigated. Such a study might be beneficial in post-ischemic resection anastomosis procedures, or in surgical revascularization.

\section{MATERIAL AND METHODS}

Eighteen rabbits weighing $2000-2500$ grams were obtained from the Research Unit and Bilharzial Research Center of Faculty of Medicine, Ain Shamus University. All animals were fasted 18 hours before commencing the experiment but had free access to water. At the beginning of the experiment rabbits were divided into two groups, nine rabbits each. Animals werc anaesthesized by intravenous injection of sodium pentobarbitol $(40 \mathrm{mg} / \mathrm{kg}$ ). All surgical procedures were performed with the animals breathing spontaneously and under complete aseptic conditions. (Fig. 1 - a, b, c, d).

\section{Group I : Ischemia Reperfusion}

Through a midline abdominal incision a single jejunal loop $(10 \mathrm{~cm})$ was delivered, all the terminal feeding branches of the superior mesenteric artery and their collaterals supplying the selected segment were occluded for 60 minutes with atraumatic vascular clamps, vessel occlusion was confirmed by loss of pulsations. The jejunal segment was returned to the peritoneal cavity and periodically irrigated with saline. At the end of the ischemic period the clamps were removed to allow 
reperfusion, the abdominal cavity was closed using monofilament polypropylene and a subcutical $2 / 0$ vicryl. Three rabbits underwent the same procedures apart from occlusion of the terminal branches of superior mesenteric artery (Sham operated).

\section{Group II : Continuous Ischemia}

Through a midline incision a single jejunal loop (10 cm length) was delivered and the terminal branches of the superior mesenteric artery and their collaterals supplying the selected segment were ligated in continuity with $4 / 0$ polygalactin, vessel occlusion was confirmed by loss of pulsations. The jejunal segment was retumed to the peritoneal cavity and irrigated with saline. The abdominal cavity was closed using monofilament polypropylene and a subcutical $2 / 0$ vicryl. Three rabbits underwent the same procedure apart from ligation of the terminal branches of the superior mesenteric artery (Sham operated).

\section{Tissue Preparation :}

On recovery from anesthesia, rabbits were allowed free access to water and soft diet to avoid abdominal over distention. Rabbits were sacrificed after 24 hours, the abdominal cavity was incised and the ischemic jejunal scgment and the segment distal to it were resected. Specimens wcre immediately fixed in $10 \%$ formol saline and embedded in paraffin wax, Serial paraffin sections were cut at $5 \mu \mathrm{m}$ in thickness and stained with haematoxylin and eosin and Wilder Sliver stain for reticular fibers. Other specimens $1 \mathrm{~mm} 3$ in thickness were fixed in $2.5 \%$ glutraldehyde in phosphate buffer and proceeded for scanning electron microscopic studies. The specimens were examined and photographed with Philips scanning electron microscope (XL 30).

\section{Image Morphometry :}

The villus height, thickness as well as, the height of the columnar epithelial cells (enterocytes) were measured using Leica Qwin 500 Image Analyzer. Morphometric analysis was carried out on routine haematoxylin and eosin stained slides. The height of the villus was measured by drawing a line from the tip of the villus to the base. The villus thickness was determined by measuring the width of the villus at several points throughout its length. The height of enterocytes was measured from surface of the cell to base passing through the nucleus. The height of villus and thickness were measured on magnification (X50) while the height of enterocytes on 
magnification (X 400). The measurements were repeated on several villi in serial sections. The data were represented as mean \pm standard deviation and were analyzed using student t-test.

\section{Immunohistochemical procedure :}

Paraffin sections $5 \mu \mathrm{m}$ in thickness were mounted on slides coated with polysine, placed in $0.5 \%$ hydrogen peroxide methanol, washed with T.B.S buffer (PH. 7.5) then placed in diluted serum. Sections were incubated with the primary antibody. Nitric oxide synthase - 3 mouse monocolonal antibody (Nova Castra Laboratories), washed with T.B.S buffer for 5 minutes twice, incubated with biotinylated secondary antibody (Nova castra laboratories) after incubation sections were washed with T.B.S buffer for 5 minutes. Additional slides were treated with non immune serum instead of the primary antibody and were used as controls.

Endothelial cells with positive reactivity for nitric oxide synthase (NOS) showed brown colour in the cytoplasm and membranes.

\section{RESULTS}

\section{The control groups (Sham Operated) :}

Light microscopic examination of the jejunum of rabbits of the control groups (Sham operated) clarified that the jejunal villi were finger-like processes. the mean height of villi was $321.070 \pm 132.475$ and the mean thickness was $60.568 \pm 4.932$ (Tables 1.2). Each villus was lined with tall columnar epithelial cells (enterocytes) with mean height $99.349 \pm 14.460$ (Table 3). The enterocytes exhibited basal oval vesicular nuclei. At the surface, the epithelial cells were covered with homogencous striated brush border (Fig. 2). Goblet cells were interposed at intervals between the columnar cells. They were rounded in shape with eccenteric nuclei (Fig. 3). Silverstained sections showed that the core of villi contained fine, elongated and continuous network of reticular fibers along the entire core (Fig. 4).

Scanning electron microscopic examination further revealed that the jejunum of rabbits of control groups was studded with villi; in some areas the villi were closely packed together. However, each villus had well-defined clear outlines and regular orientation (Fig. 5). The surface of the villi was formed by columnar epithelial cells. The tips of the closely packed microvilli of the columnar cells gave a slightly pebbled appearance to the surface. The pebbled surface was broken occasionally by small pits representing the goblet cell orifices (Fig. 6). 
Immunohistochemical examination revealed strong nitric oxide synthase reaction in the endothelial cells of blood vessels within the core of the villi. The reaction was detected mainly in apical parts of the villi and to a lesser extent in the basal parts of villi (Fig. 7).

\section{Group I : Ischemia Reperfusion}

\section{A) Ischemic Segment :}

Light microscopic examination of the jejunum of rabbits of group I subjected to ischemia-reperfusion revealed that in the ischemic segment the general architecture of the villi was largely preserved. The villi were short and the mean height was significantly reduced $(214.051 \pm 53.686 \mathrm{P}<0.01)$ ( Table 1). However, the mean thickness was significantly increased $(84.971 \pm 36.86 \mathrm{P}<0.05$ ) (Table 2), Moreover, the typical striated brush border was indistinct and ill-defined. The enterocytes were significantly reduced in height $(52.239 \pm 6.56 \mathrm{P}<0.001)$ (Table 3$)$. The pattern of organization of enterocytes was distorted and numerous cells were detached and lifted from the villus stroma. Goblet cells were infrequently encountered (Fig. 8). The core of the villi manifcsted mononuclear cellular infiltration, amorphous eosinophilic material and aggregation of red blood cells (Figs. 8, 9). Occasionally, somc of the amorphous material and the red blood cells passed into the intestinal lumen through the dissociated enterocytes (Fig. 8). Less frequently vacuolated areas were noticed in the core of the villi (Fig. 9). Silver-stained sections revealed that the reticular fibers were partially disrupted and compressed along the sides of the villi (Fig. 10).

Scanning clectron microscopic studies clarified a varicty of surface alterations. The villi were frequently fused together with ill-defined boundaries and irregular orientation. The apical parts of the villi were either irregular and manifested small knobs or were partially detached (Fig. 11). The surface of villi showed marked sloughing of the epithelial cells and ill-defined microvilli with loss of the pebbled appearance. Goblet cells were rarely encountered (Fig. 12). The ischemic jejunal segment showed few flattened irregular shaped areas without surface villi (Fig. 11). Immunohistochemical examination clarified that nitric oxide synthase . zaction in the endothelial cells within the core was weak as compared with the control group and occurred at interrupted wide intervals (Fig. 13).

\section{B) Distal Segment :}

Light microscopic examination of the jejunal segment distal to the ischemic segment revealed that the mean height of villi was $285.578 \pm 90.343$ showing non 
significant variation from the control group ( $\mathrm{P}>0.05$ ) (Table 1 ). The mean thickness of villi was $47.332 \pm 6.452$ showing significant variation than the control ( $P<$ 0.001 ) (Table 2). On comparing the distal segment to the ischemic segment, it was clear that the height of villi in the distal segment was significantly higher than in ischemic segment $(P<0.05)$ (Table 1$)$. The mean thickness of villi was significantly reduced compared with the ischemic segment $(P<0.01$ ) (Table 2 ). Though the villi generally exhibited intact brush border, numerous goblet cells and regular arrangement of enterocytes, yet the height of enterocytes was $65.145 \pm 8.782$ showing significant decrease from the control $(\mathrm{P}<0.001)$ (Table 3$)$. On comparing with the ischemic segment the height of enterocytes in the distal segment showed significant increase $(\mathrm{P}<0.001)$ (Table 3 ). The core of the villi exhibited marked mononuclear ccllular infiltration (Fig. 14). Moreover, silver-stained scctions clarificd the presence of extensive network of thickened branching reticular fibers particularly in the basal parts of the villi (Fig. 15).

Scanning electron microscopic cxamination revealed that jejunal segment distal to the ischemic segment was studded with villi with preserved outlines. However, numerous villi were irregularly oriented (Fig. 16). The surface was pebbled with numerous microvilli and prominent goblet cclls which often formed multiple aggregates (Fig. 17). Immunohistochemical examination clarified that nitric oxide synthase reaction was intensified particularly in the endothelial cells in the apical parts of the villi (Fig. 18).

\section{Group II : Continuous Ischemia}

\section{A) Ischemic Segment :}

Light microscopic examination of jcjunum of rabbits of group II subjected to continuous ischemia showed marked exacerbation of the mucosal injury. Most of the villi were atrophied, denuded and altered in shape with loss of their finger-like appearance (Fig. 19). The mean height of the villi was $81.136 \pm 38.216$ showing significant decrease than the height of the villi of both the control $(P<0.001)$ and the group subjected to ischemia reperfusion $(P<0.001)$ (Table 1). Regarding the mean thickness of the villi it was $40.66 \pm 17.92$ showing again significant decrease than the thickness of villi of both the control group $(\mathrm{P}<0.001)$ and than the group subjected to ischemia reperfusion $(\mathrm{P}<0.001)$ (Table 2$)$. The pattern of organization of enterocytes was completely lost (Fig. 19). The mean height of enterocytes was 54.16 +8.32 showing significant decrease than the control $(P<0.001)$. However, on 
comparing with the group subjected to ischemia reperfusion, the height of enterocytes did not show significant variation $(P>0.05$ ) (Table 3 ).

Furthermore, numerous enterocytes were detached along the entire length of the villi. The detached cells had condensed or pyknotic nuclei (Figs. 19, 20). Large areas manifested ulceration and mononuclear cellular infiltration (Fig. 21). The villus stroma showed cxtensive hemorrhage and marked mononuclear cellular infiltralion ( Figs. 19,21), Silver-stained sections clarified almost complete disruption of the reticular fibers as they appeared thin, short and fragmented (Fig. 22).

Scanning electron microscopic examination further demonstrated that the villi were atrophicd, irregularly oriented and the apex of the villi was completely distorted. The jejunum showed wide areas of ulceralion with complete loss of the surface epithelium and microvilli (Fig. 23). Immunohistochemical studies showed that the nitric oxide synthase reaction in the endothelial cells was extremely weak and localized (Fig. 24).

\section{B) Distal Segment :}

Light microscopic examination of the jejunal segment distal to the segment subjected to continuous ischemia revealed that the villus structure was generally preserved apart from broadening and flattening of the apex of the villi (Fig. 25). The mean height of the villi was $186.35 \pm 74.53$ manifesting significant decrease than the control $(P<0.01$ ) (Table 1). The mean thickness of the villi was $88.74 \pm 33.49$ showing significant increase than the control $(\mathrm{P}<-0.01$ ) (Table 2). On comparing with the ischemic segment, the height of the villi in the distal segment showed significant increase $(\mathrm{P}<0.001)$ (Table 1 ). The mean thickness of the villi showed also significant increase $(P<0.001)$ (Table 2$)$. Though the enterocytes were not detached but they exhibited few condensed nuclei (Fig. 25). Moreover, the height of enterocytes was $68.60 \pm 8.35$ showing significant decrease than the control $(P<0.001)$ (Table 3). However, on comparing with the ischemic segment the height of enterocytes was significantly higher $(P<0.001$ ) (Table 3 ). The core of villi showed severe, mononuclear cellular infiltration (Fig. 25). Silver-stained sections revealed that the reticular fibers were densely arranged in the basal parts of the villi (Fig. 26).

Scanning electron microscopic examination demonstrated that the jejunum was studded with closely packed villi and some villi showed detached apices. (Fig. 27). The characteristic finding in the distal segment was the presence of filamentous mucous threads encroaching on the villi (Fig. 28). Immunohistochemical studies 
clarified that the nitric oxide synthase reaction was intense particularly in the endothelial cells in the apical parts of the villi (Fig. 29).

Table 1 : The Height of Villi :

\begin{tabular}{|c|c|c|c|c|}
\hline & $\begin{array}{c}\text { Ischemic segment in } \\
\text { ischemia reperfusion } \\
\mathrm{M}: 214.051 \\
\mathrm{SD}: 53.686\end{array}$ & $\begin{array}{c}\text { Distal segment in } \\
\text { Ischemia reperfusion } \\
\text { M: } 285.578 \\
\text { SD }: 90.343\end{array}$ & $\begin{array}{l}\text { Ischemic segment in } \\
\text { continuous ischemia } \\
M: 81.136- \\
\text { SD }: 38.216\end{array}$ & $\begin{array}{l}\text { Distal segment in } \\
\text { continuous ischemia } \\
M: 186.359 . \\
\text { SD }: 74.531\end{array}$ \\
\hline $\begin{array}{l}\text { Control } \\
\text { M: } \mathbf{3 2 1 . 0 7 0} \\
\text { SD: } 132.475\end{array}$ & $\begin{array}{c}t: 2.581 \\
P<0.01 \\
H S\end{array}$ & $\begin{array}{c}t: 0.734 \\
p>0.05 \\
\quad N S\end{array}$ & $\begin{array}{c}\mathrm{t}: 6.252 \\
\mathrm{P}<0.001 \\
\mathrm{HS}\end{array}$ & $\begin{array}{l}t: 2.939 \\
P<0.01 \\
\quad H S\end{array}$ \\
\hline $\begin{array}{l}\text { Ischemic } \\
\text { segment in } \\
\text { ischemia } \\
\text { reperfusion }\end{array}$ & & $\begin{array}{c}\mathrm{t}:-2.322 \\
\mathrm{P}<0.05 \\
\mathrm{~S}\end{array}$ & & \\
\hline $\begin{array}{l}\text { Ischemic } \\
\text { segment in } \\
\text { continuous } \\
\text { ischemia }\end{array}$ & $\begin{array}{c}t: 7.176 \\
P<0.001 \\
\text { HS }\end{array}$ & & & $\begin{array}{c}t: 9.889 \\
P<0.001 \\
\text { HS }\end{array}$ \\
\hline
\end{tabular}

HS : Highly Significant.

$S$ : Significant.

NS : Non-Signilicant.

1 : Sludent's "t" Iest. 
Table 2 : The Thickness of Villi :

\begin{tabular}{|c|c|c|c|c|}
\hline & $\begin{array}{c}\text { Ischemic segment in } \\
\text { ischemia reperfusion } \\
\mathrm{M}: \mathbf{8 4 . 9 7 1} \\
\mathrm{SD}: \mathbf{3 6 . 8 6 3}\end{array}$ & $\begin{array}{l}\text { Distal segment in } \\
\text { ischeminia reperfusion } \\
M: 47.332- \\
\text { SD }: 6.452\end{array}$ & $\begin{array}{c}\text { Ischemic segment in } \\
\text { continuous ischenia } \\
\mathrm{M}: \mathbf{4 0 . 6 6 5} \\
\mathrm{SD}: \mathbf{1 7 . 9 2 7}\end{array}$ & $\begin{array}{l}\text { Distal segment in } \\
\text { continuous ischemia } \\
\mathrm{M}: \mathbf{8 8 . 7 4 3} \text {. } \\
\mathrm{SD}: \mathbf{3 3 . 4 9 2}\end{array}$ \\
\hline $\begin{array}{l}\text { Control } \\
\text { M: } 60.568 \\
\text { SD: } 4.932\end{array}$ & $\begin{array}{c}\mathrm{t}:-2.276 \\
\mathrm{P}<0.05 \\
\mathrm{~S}\end{array}$ & $\begin{array}{c}1: 5.556 \\
P<0.001 \\
\text { HS }\end{array}$ & $\begin{array}{c}1: 3.717 \\
P<0.001 \\
\quad \text { HS }\end{array}$ & $\begin{array}{c}\mathrm{t}: 2.880 \\
\mathrm{P}<0.01 \\
\mathrm{HS}\end{array}$ \\
\hline $\begin{array}{l}\text { Ischemic } \\
\text { segment in } \\
\text { ischemia } \\
\text { reperfusion }\end{array}$ & & $\begin{array}{c}\mathrm{t}: 3.335 \\
\mathrm{P}<0.01 \\
\mathrm{HS}\end{array}$ & & \\
\hline $\begin{array}{l}\text { Ischemic } \\
\text { segment in } \\
\text { continuous } \\
\text { ischemia }\end{array}$ & $\begin{array}{c}t: 3.956 \\
P<0.001 \\
\text { HS }\end{array}$ & & & $\begin{array}{c}t:-4.6993 \\
\mathrm{P}<0.001 \\
\mathrm{HS}\end{array}$ \\
\hline
\end{tabular}

Table 3 : The Height of Enterocytes :

\begin{tabular}{|c|c|c|c|c|}
\hline & $\begin{array}{l}\text { Ischemic segment in } \\
\text { ischemia reperfusion } \\
M: 52.239 \\
S D: 6.560\end{array}$ & $\begin{array}{l}\text { Distal segment in } \\
\text { ischemia reperfusion } \\
\text { M: } 65.145 \text { - } \\
\text { SD : 8.782 }\end{array}$ & $\begin{array}{c}\text { Ischemic segment in } \\
\text { continuous ischemia } \\
M: 54.164 . \\
\text { SD:8.326 }\end{array}$ & $\begin{array}{l}\text { Distal segment in } \\
\text { continuous ischemia } \\
\text { M:68.600- } \\
\text { SD : 8.358 }\end{array}$ \\
\hline $\begin{array}{l}\text { Control } \\
\text { M: } 99.349 \\
\text { SD: } 14.46\end{array}$ & $\begin{array}{c}1: 9.491 \\
P<0.001 \\
\quad \text { HS }\end{array}$ & $\begin{array}{c}t: 6.775 \\
P<0.001 \\
\text { HS }\end{array}$ & $\begin{array}{c}1: 9.380 \\
P<0.001 \\
\quad H S\end{array}$ & $\begin{array}{c}1: 6.377 \\
P<0.001 \\
\text { HS }\end{array}$ \\
\hline $\begin{array}{l}\text { Ischemic } \\
\text { segment in } \\
\text { ischemia } \\
\text { reperfusion }\end{array}$ & & $\begin{array}{l}t:-3.782 \\
P<0.001 \\
\quad H S\end{array}$ & & \\
\hline $\begin{array}{l}\text { Ischemic } \\
\text { segment in } \\
\text { continuous } \\
\text { ischemia }\end{array}$ & $\begin{array}{c}t:-5929 \\
P>0.05 \\
N S\end{array}$ & & . & $\begin{array}{c}t:-4.2381 \\
P<0.001 \\
H S\end{array}$ \\
\hline
\end{tabular}




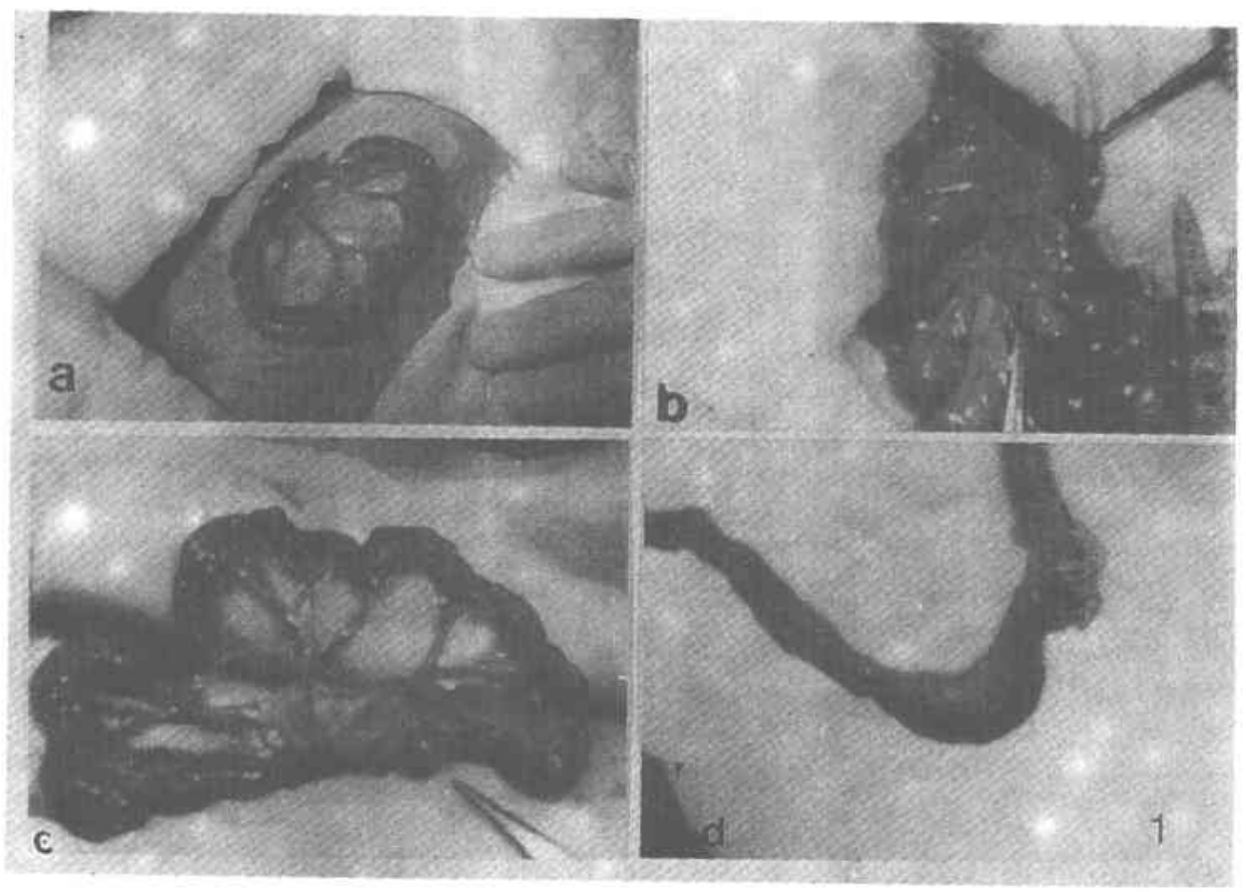

Fig. (1) : An illustration showing :

a) The selected Jejunal segment.

b) The ligation of the terminal blood vessels.

c) The occlusion of the terminal blond vessels.

d) The jejunal segments following Ischemla. 


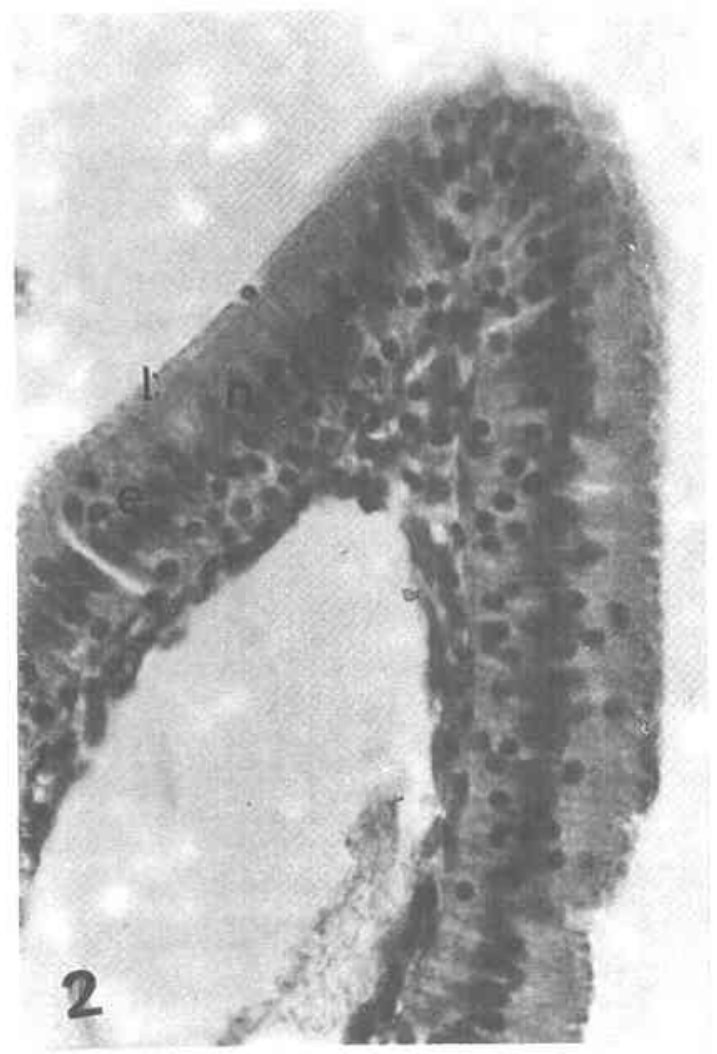

Fig. (2) : A photomicrograph of a section of the jejunum of control rabbit showing finger shaped villus lined by enterocytes (e) with oval basal vesicular nuclei (n) Notice the brush border (b).

(Hx. \& E., x 400) 


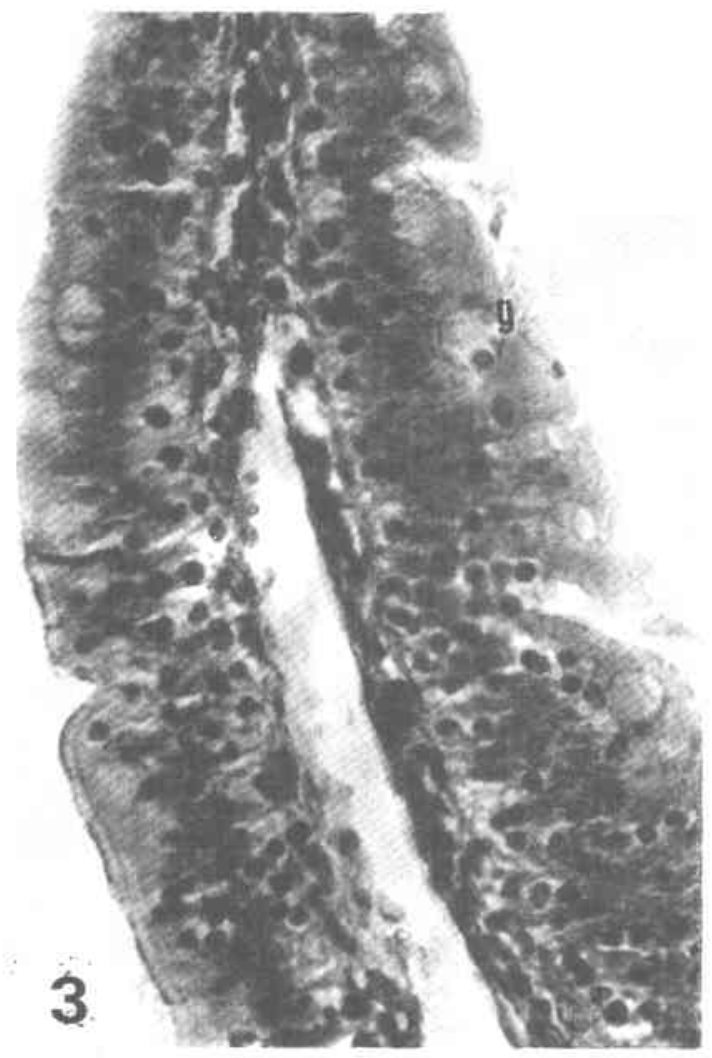

Fig. (3) : A photomicrograph of a section of the jejunum of rabbit of control group showing rounded goblet cells with eccentric nuclei $(\mathrm{g})$.

(Hx. \& E., x 400) 


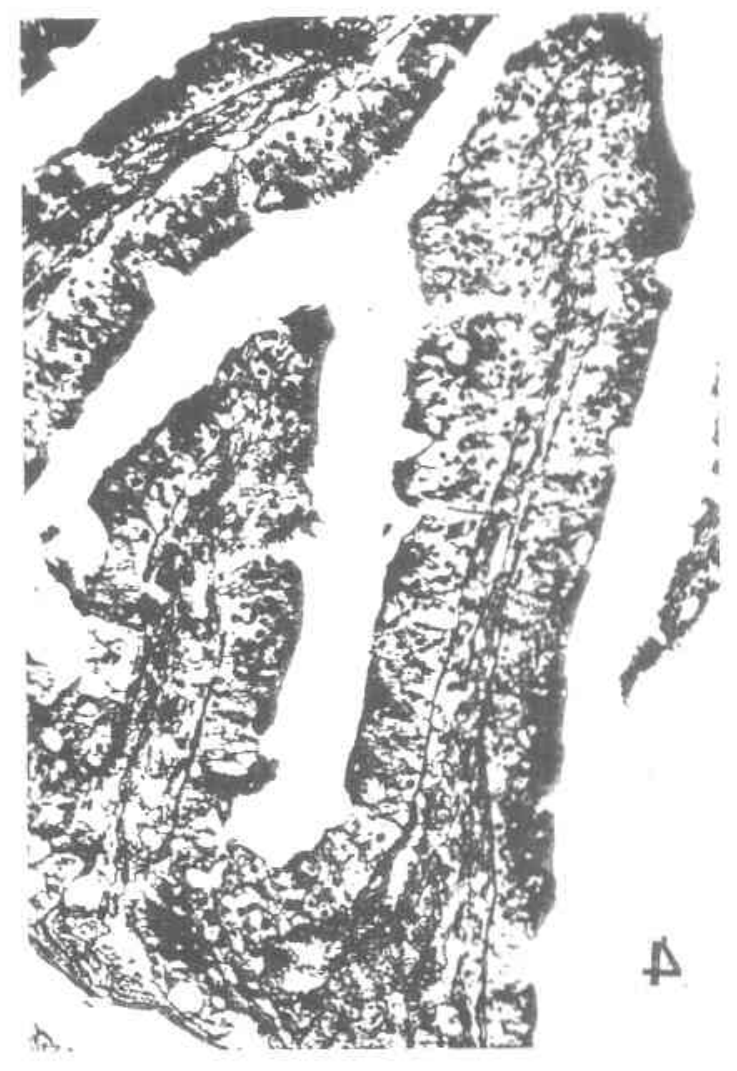

Fig. (4) : A photomicrograph of a seclion of jejunum of rabhit of the control group showing fine elongated. continuous rẹicular fibers $(\uparrow)$.

(Wilder Stain, $x$ 200) 


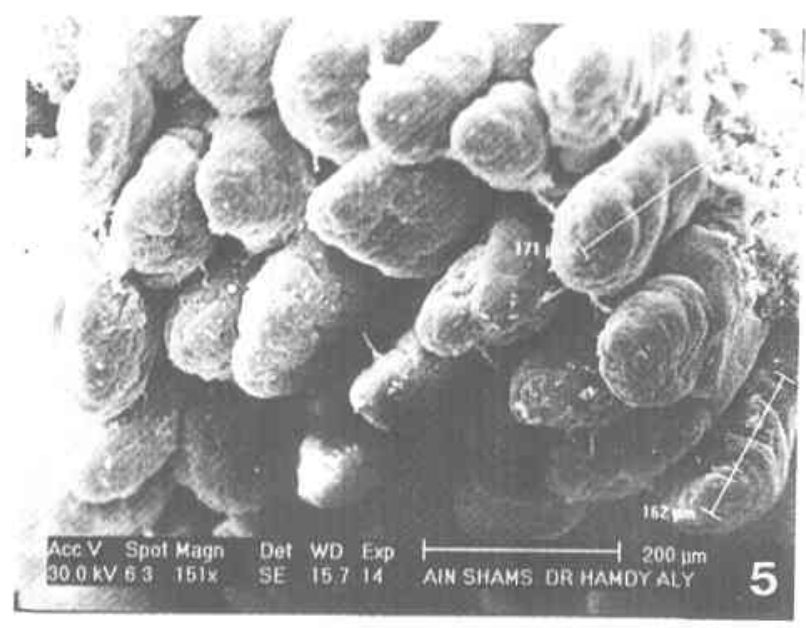

Fig. (5) : A scanning electron micrograph of jcjunum of rabbit of the control group. Notice the closely packed, regularly oriented villi with well defined outlines.

(Scale bar $200 \mu \mathrm{m}$ )

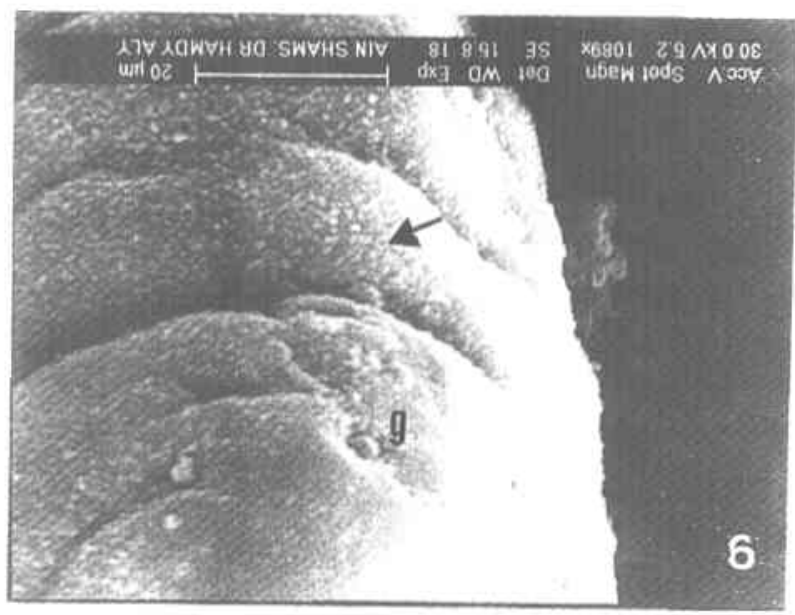

Fig. (6) : A scanning electron micrograph of jejunum of rabbit of the control group showing the pebbled surface of the villi $(\uparrow)$. Notice the goblef cells $(\mathrm{g})$.

(Scale bar $20 \mu \mathrm{m}$ ) 


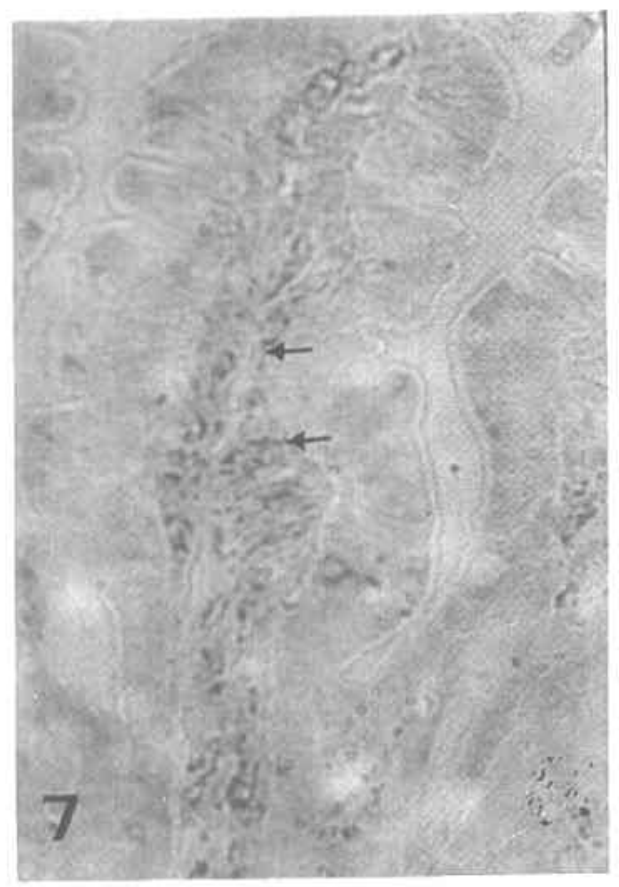

Fig. (7) : A photomicrograph ot a secetion of jejunum of rabbit of the control group. Notice the nitric oxide synthase reaction in the endothelial colls along the entire core of the villus

(NOS imnunc)-staining, $\mathrm{x}+(\mathrm{x})$
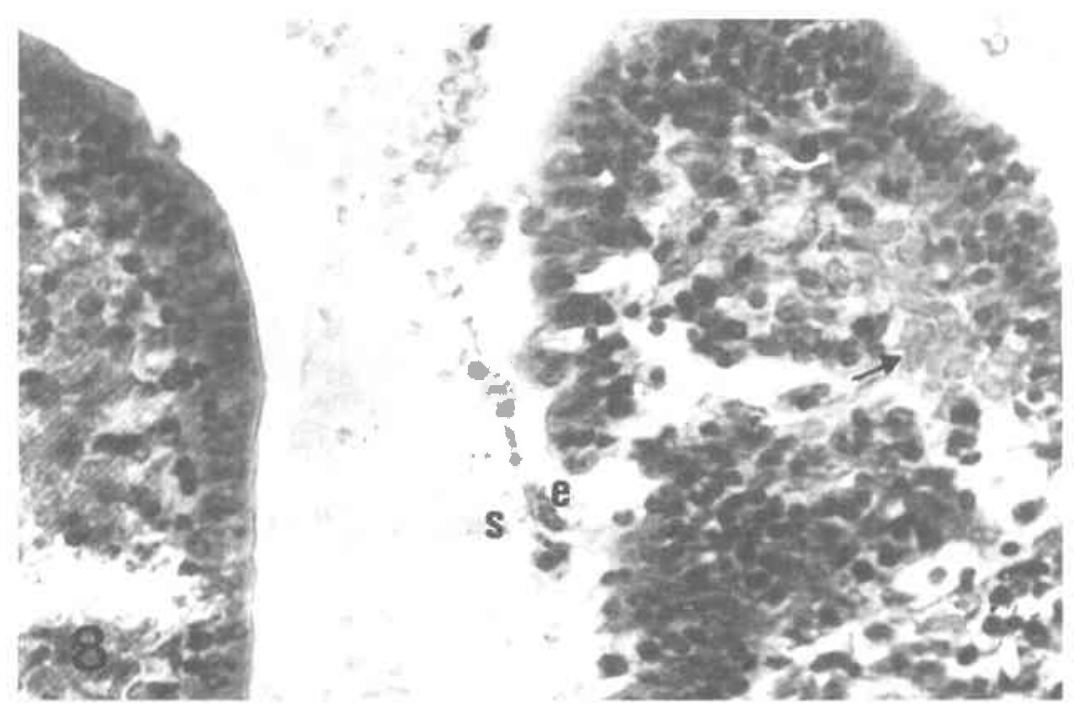

Fig. (8) : A photomicrograph of a section of the ischenic segment of jejunum of rabbit of group I showing distorted pattern of enterocytes. Notice the detached enterocytes (e), eosinophilic material (s) and the red blood cells ( $T$ ).

(Hx.\& E., x 400) 


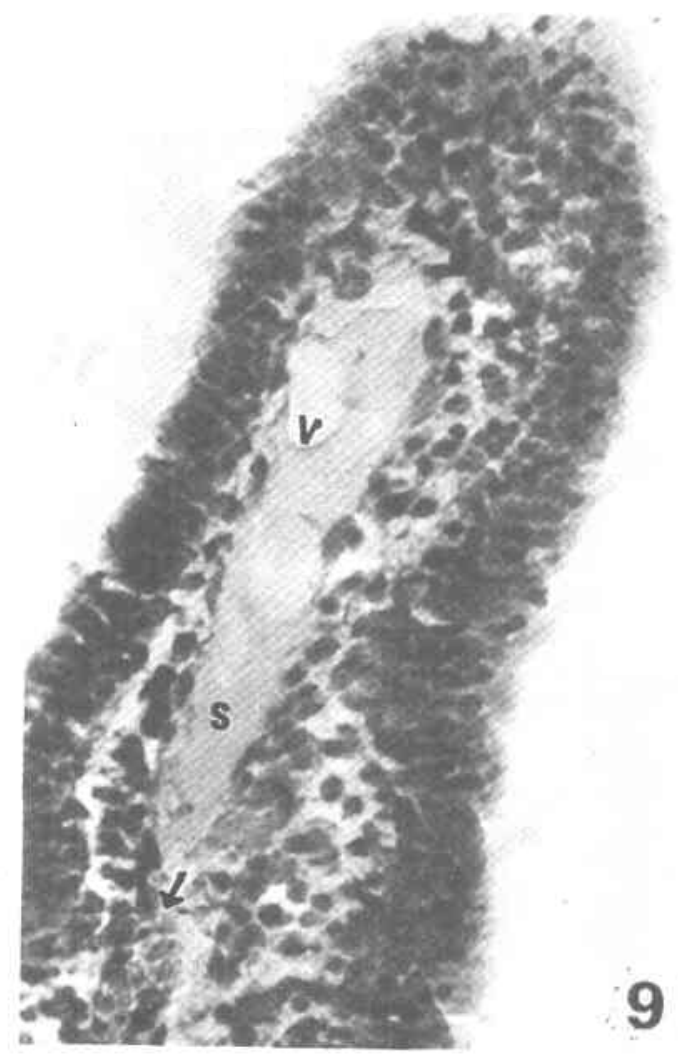

Fig. (9) : A photomicrograph of a section of the ischemic segment of jejunum of rabbit of group I showing cosinophilic material (s) vacuolation (v) and few red blood cells ( $\uparrow$ ). (Hx. \& E., x 400) 


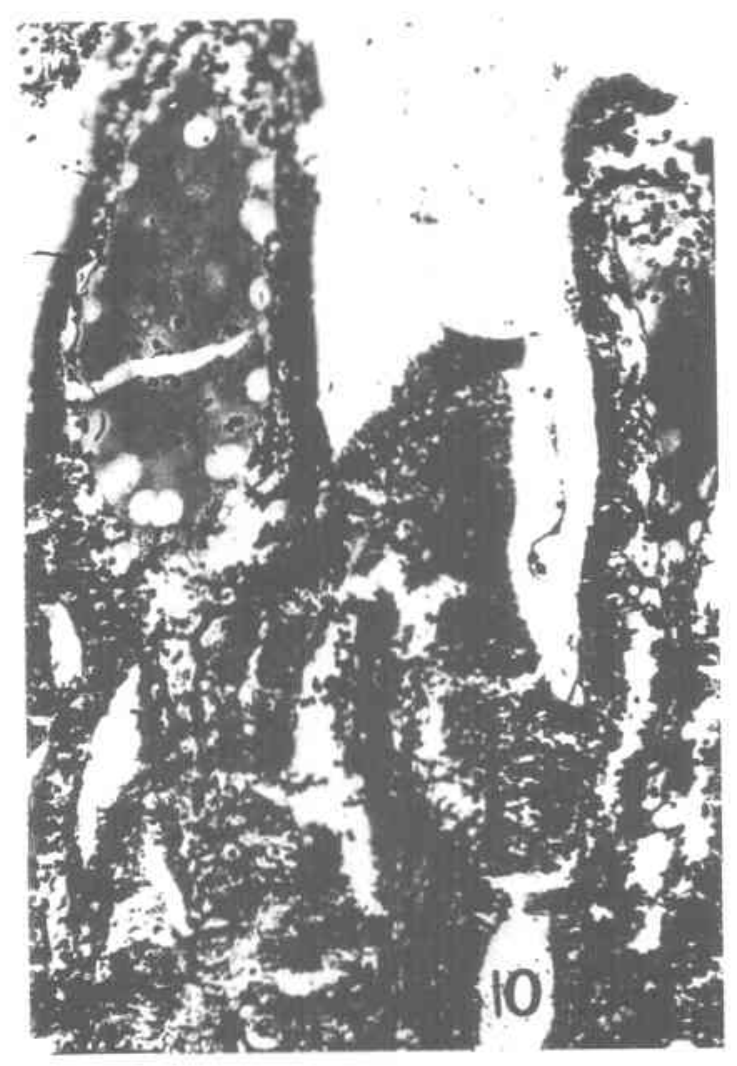

Fig. (10): A photonicrograph of a section of the ischemic segment of jejunum of group 1. Notice, the partial disnuption and compression of the reticular fiber $(T)$

(Wilder stain, $\mathrm{x} 200$ ) 


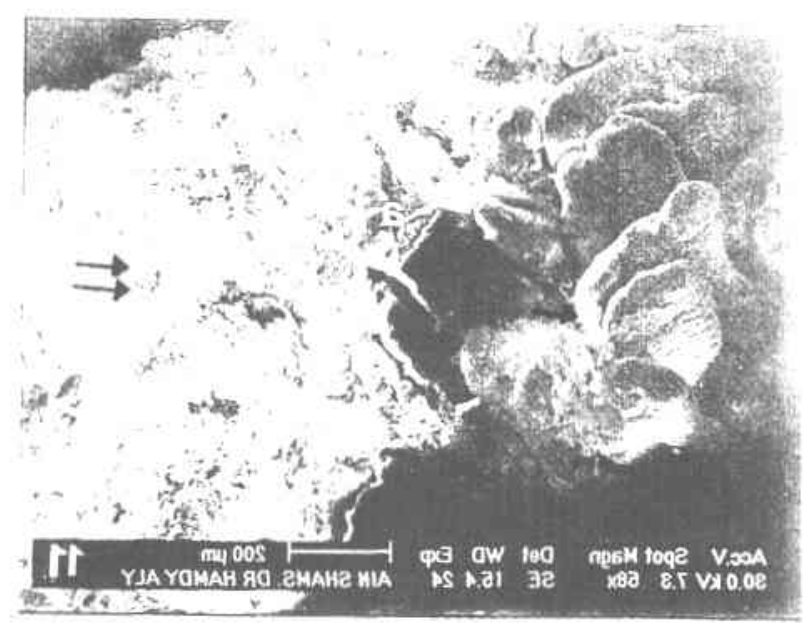

Fig. (11) : A scanning electron micrograph of the ischemic segment of jejunum of rabbit of group (I) showing the villi with ill defined boundaries ( $\uparrow$ ) and detached apex (a). Notice the plain area without sur-
face villi $(\uparrow \uparrow$ ).

(Scale bar $200 \mu \mathrm{m}$ )

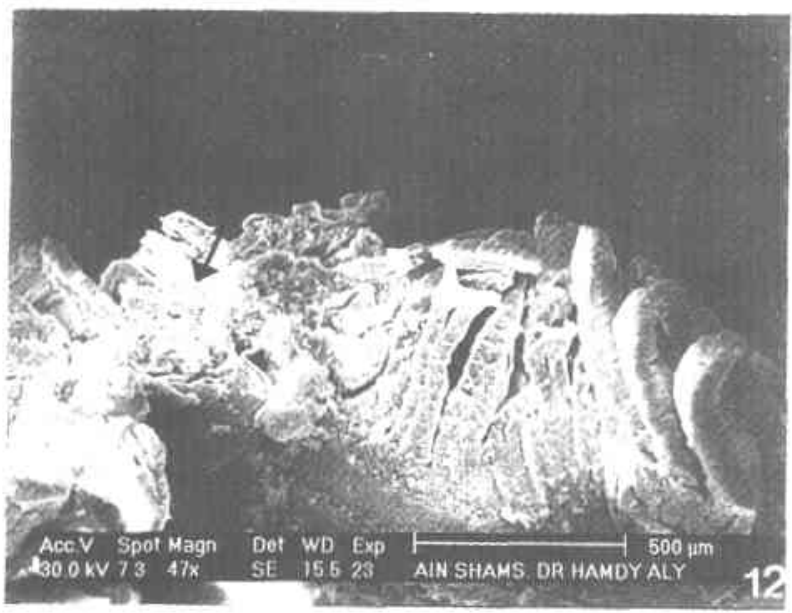

Fig. (12) : A scanning electron micrograph of the ischemic segment of jejunum of rabbit of group I showing sloughing of surf ace epithelium and microvilli $(\uparrow)$.

(Scalc bar $500 \mu \mathrm{m}$ ) 


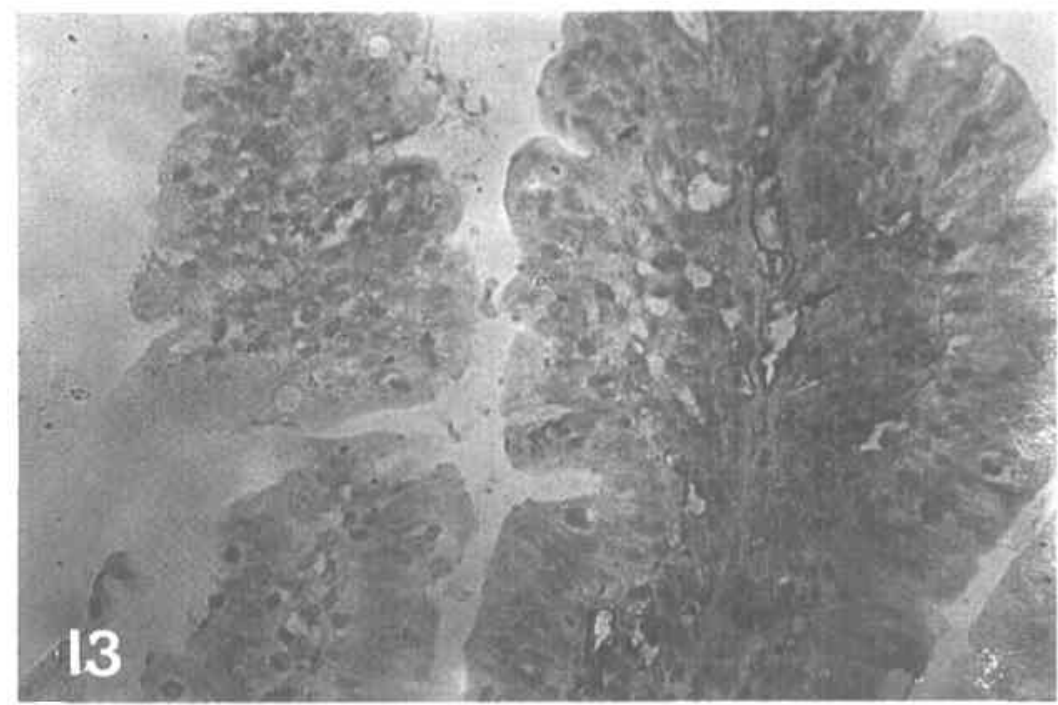

Fig. (13) : A photmicrograph of a section of the ischenic segnent of jejunum ol rabhit of group I showing weak nitric oxide synthase reaction $(\uparrow)$.

(NOS immuno-staining $x 400$ ) 


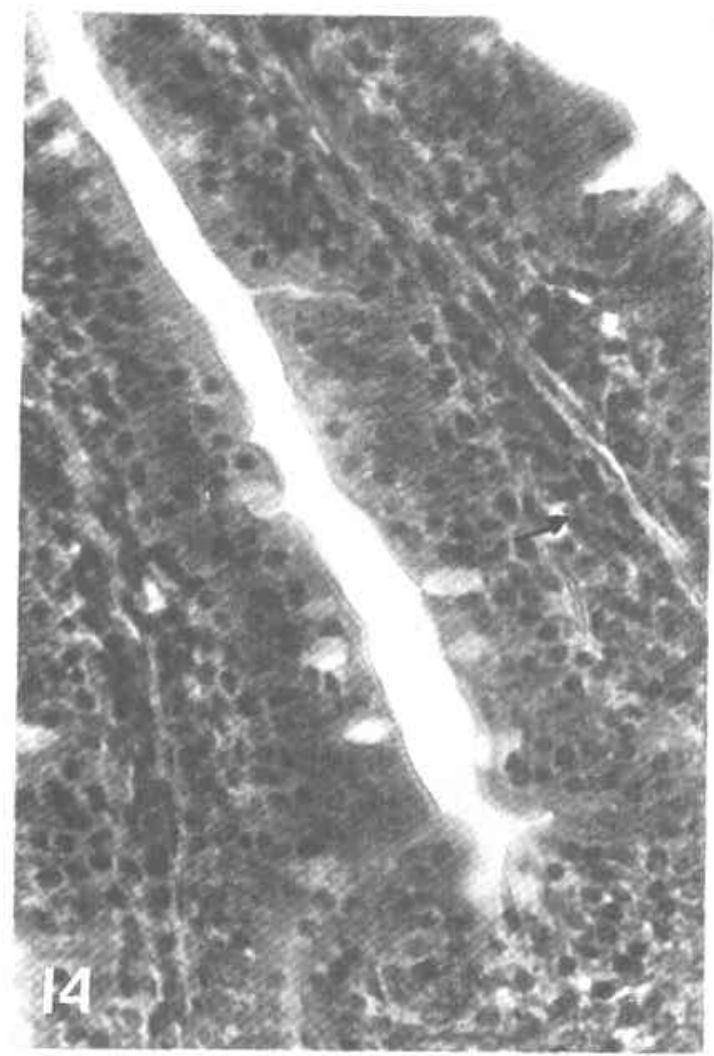

Fig. (14) : A photomicrograph of a section of the distal segment of jejunum of rabbit of group I showing marked mononuclear cellular infiltration in the core of the villi ( $($ ).

(Hx.\& E., x 400) 


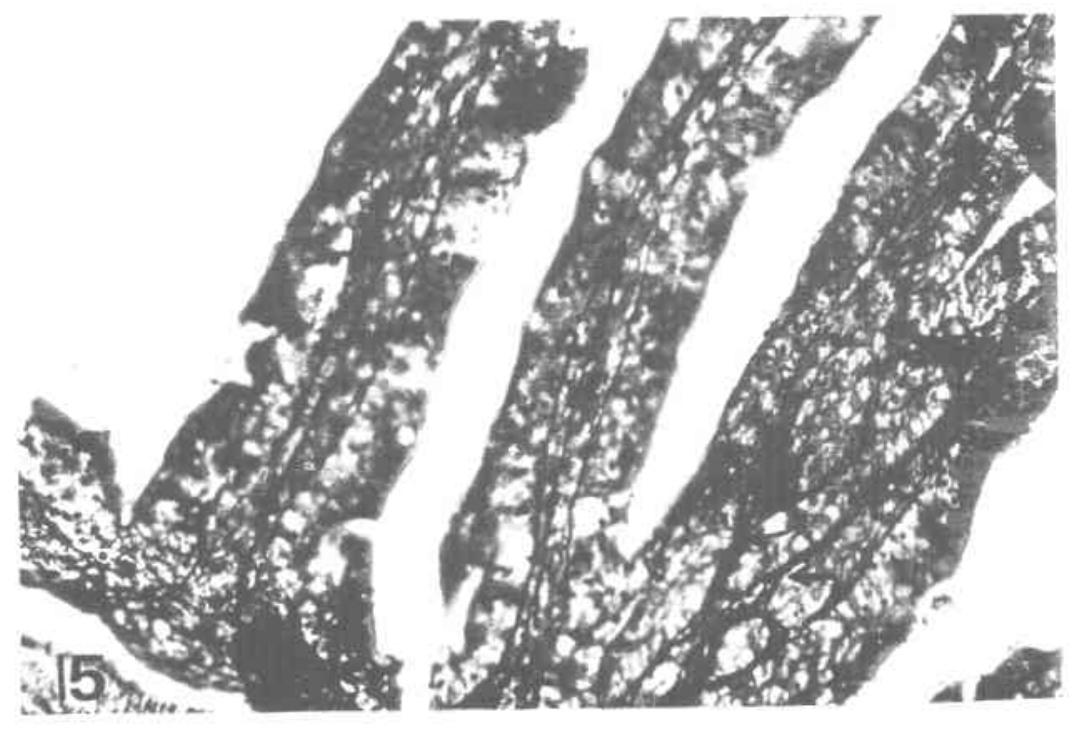

Flg. (15) : A photomicrograph of a section of the distal segment of jejunum of rabhit of group I showing thickened branching reticular fibers in basal parts of villi ( $T$ ).

(Wilder stain; $x$ 200) 


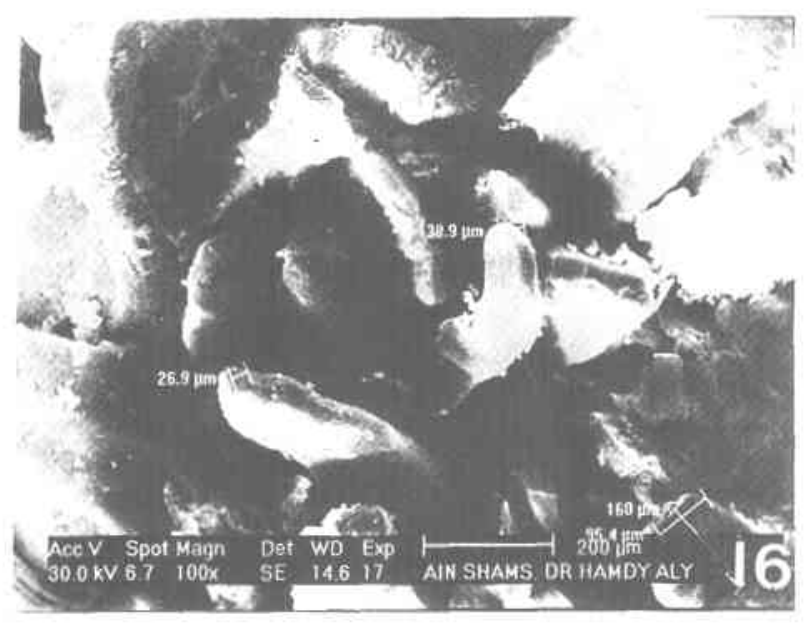

Fig. (16) : A scanning clectron micrograph of distal segnent of jejunum of rabbit of group (I). Notice the irregular orientation of villi.

(Scale bar $200 \mu \mathrm{m})$

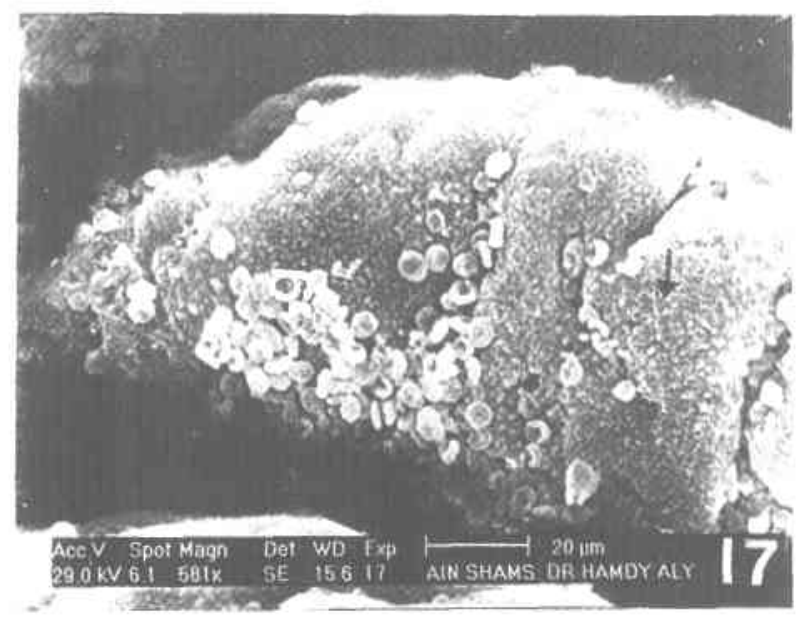

Fig. (17) : A scanning electron micrograph of distal segment of jejunum of rabbil of group 1 . Notice the aggregates of goblet cells $(\mathrm{g})$ and the pebbled surface (T).

(Scale bar $20 \mu \mathrm{m}$ ) 


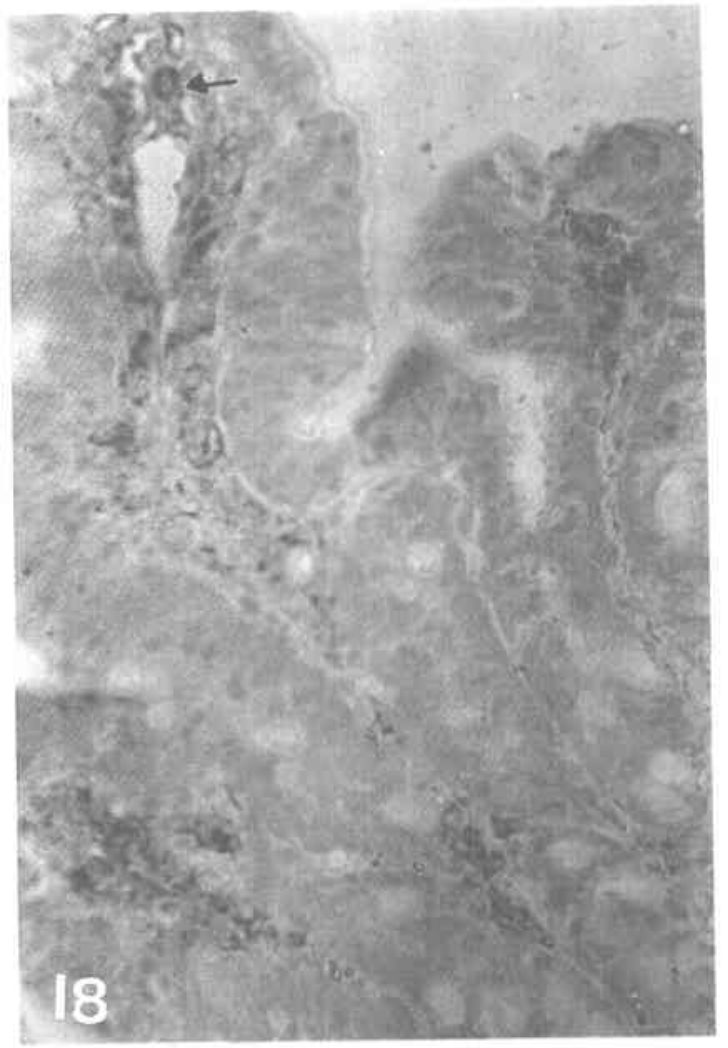

Fig. (18) : A photomicrograph of a section of the disfal segment of jejunum of rahbit of group 1 . Notice the intense nitric oxtde synthase reaction in the apical parts of the villi ( $\uparrow$ ). (NOS immuno-staining $\times 400)$ 


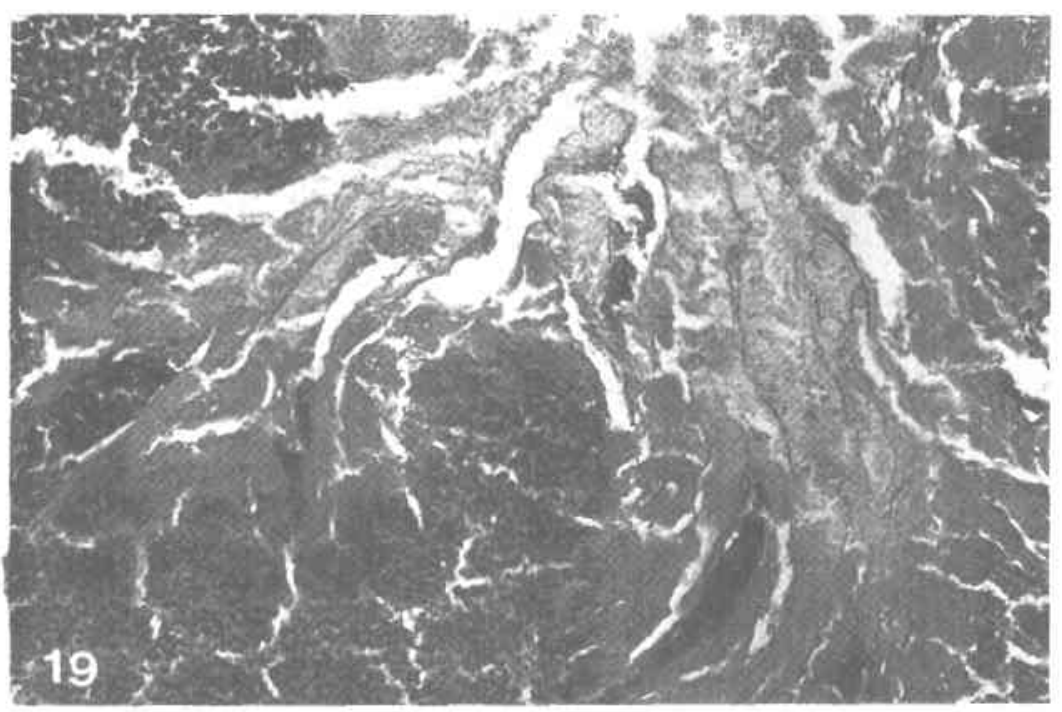

Fig. (19) : A phluhnicrograph of a section of the ischentic segment of jejunum of rabbit of group II. Notice the atrophied villi and the loss of finger like appearance.

(Ix.\& E.; $\times 200)$

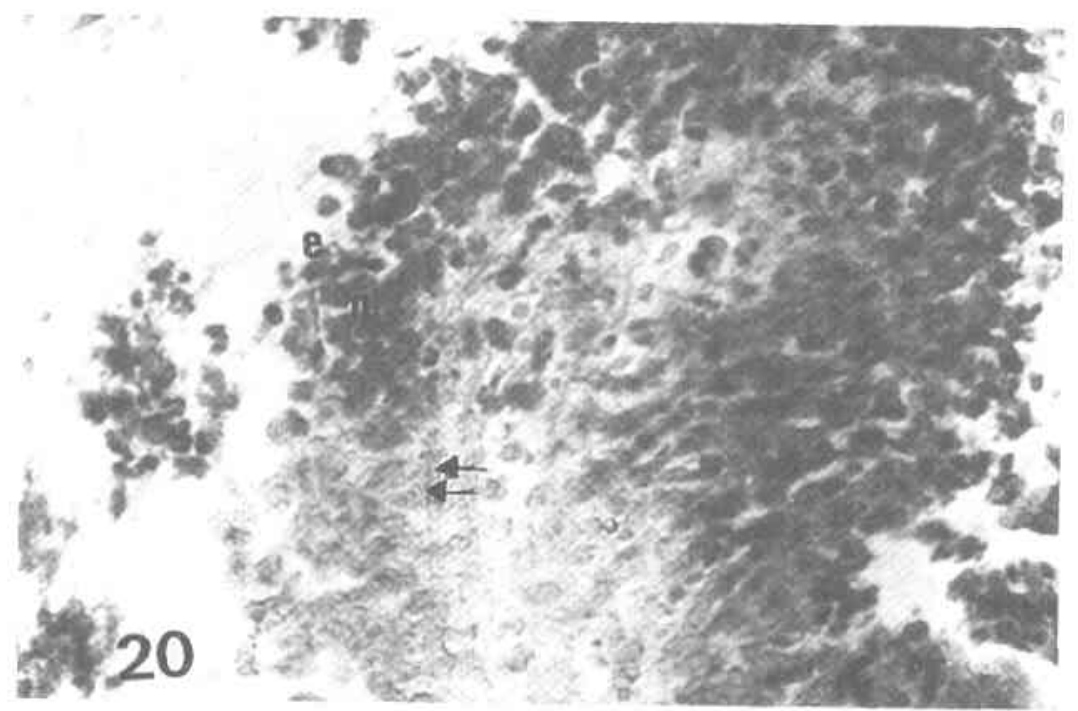

Fig. (20): A photomicrograph of a section of the ischemic segment of jejunum of rabbit of group Il showing villi with detached enterocytes $(e)$. Notice the pyknotic nuclei $(n)$ and the extensive bemorrhage $(\uparrow \uparrow)$. 


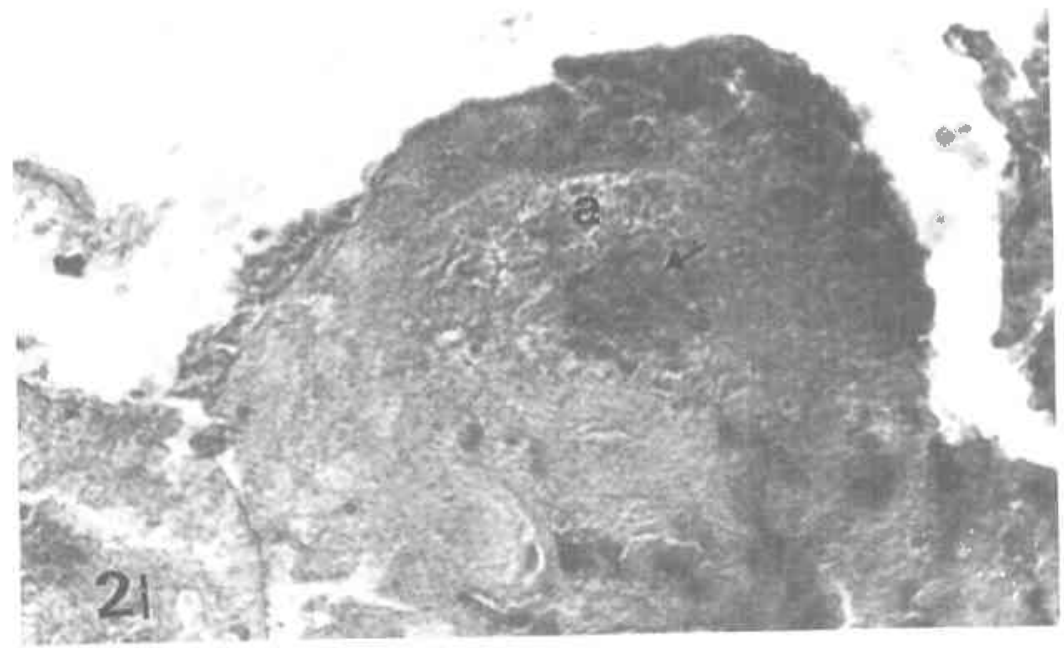

Hig. (21) : A photomicrograph of a section of the ischemic segment of jejuntm of rabbit of group II showing wide area of ulceration (a). Notice the mononuclear cellular infiliation ( $\uparrow$ ).

(IIx.\& E; $;$ 400)

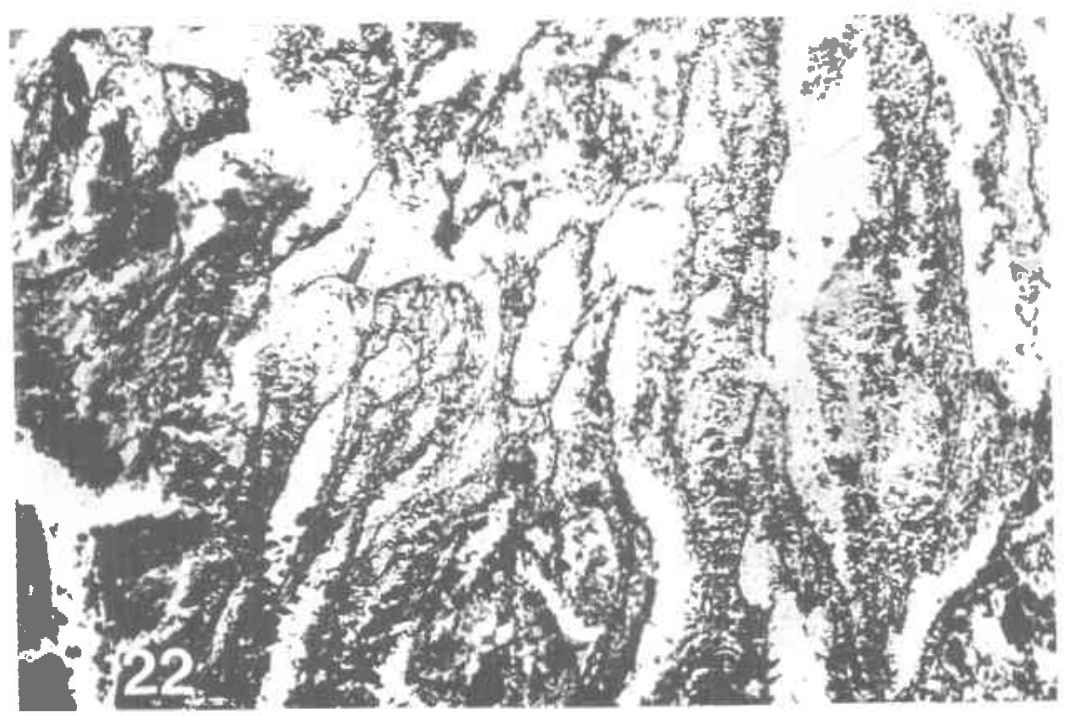

Fig. (22) : A photomicrograph of a section of the ischenic segmint of jejunum of rabbit of group lI. Notice the thin, short and fragmented reticular fibers.

(Wilder stain; $\times 200$ ) 


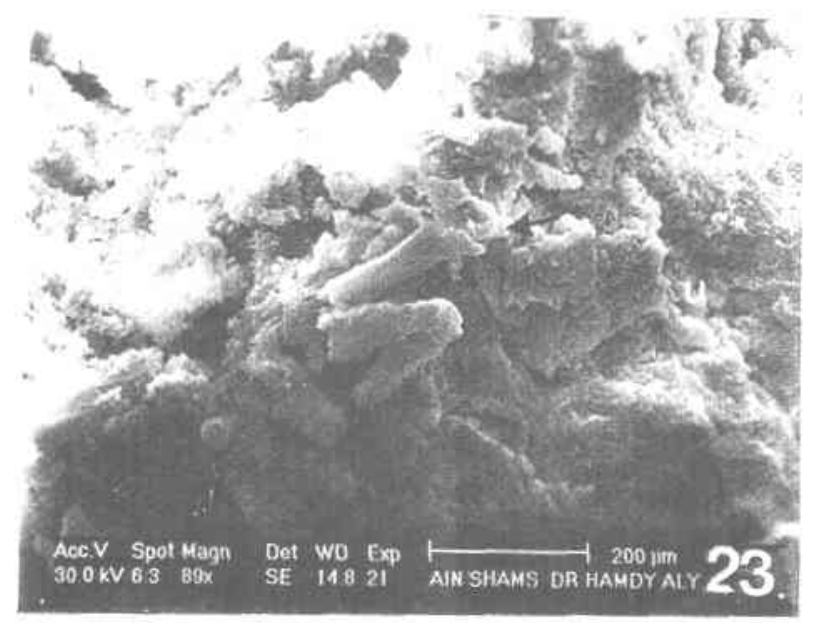

Fig. (23) : A scanning electron micrograph of ischemic segment of jejunum of rabbit of group (II) showing alrophied villi with distorted apex $(\uparrow)$. Norice the areas of ulcration (u).

(Scale bar $200 \mu \mathrm{m}$ )

Fig. (24) : A photomicrograph of a section of ischemic segment of rabbit of group II. Notice the weak, localized nitric oxide synthase reaction ( $\uparrow$ ).

(NOS imnuno-staining $x$ 400)

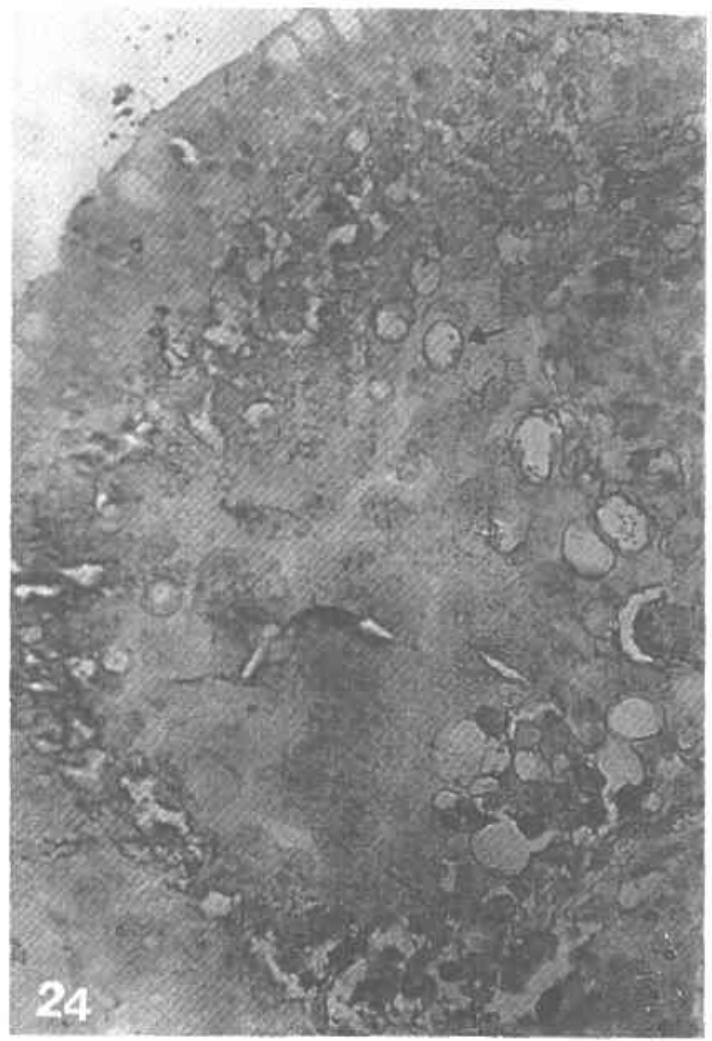

$.70-$ 


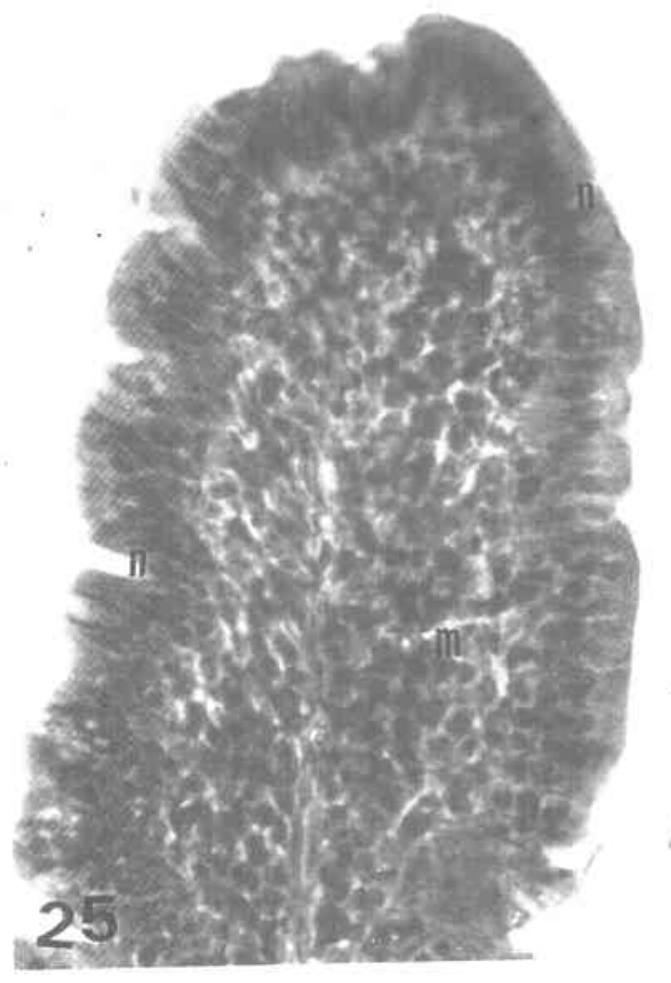

Fig. (25) : A photonicrograph of a section of the distal segment of jejunum of rabbit of group II showing the broad tip of the villi, mononuclear cellular infiltration $(\mathrm{m})$ and condensed nuclei ( $\mathrm{n}$ ).

(Hx. \& E, x 400) 


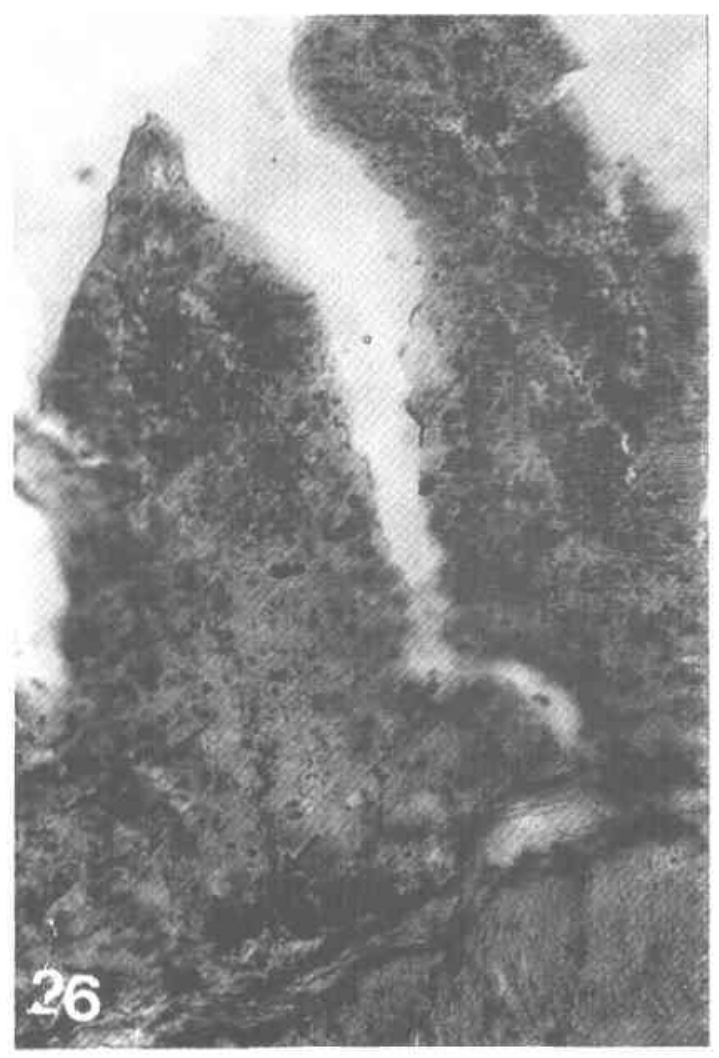

Fig. (26) : A photomicrograph of at section of the distal segment of jejunum of rabbit of group II showing dense reticular fibers ( $r$ ) in the basal parts of villi.

(Wilder stain; $x$ 200) 


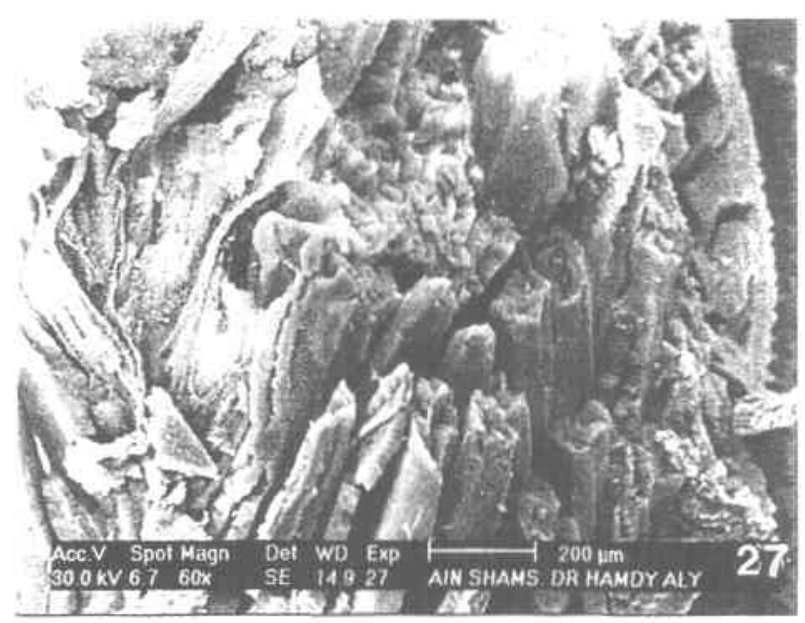

Fig. (27) : Scanning electron micrugraph of the distal segment of jejunum of rabbit of group (II) showing villi with detashed apex.

(Scale bar $200 \mu \mathrm{m}$ )

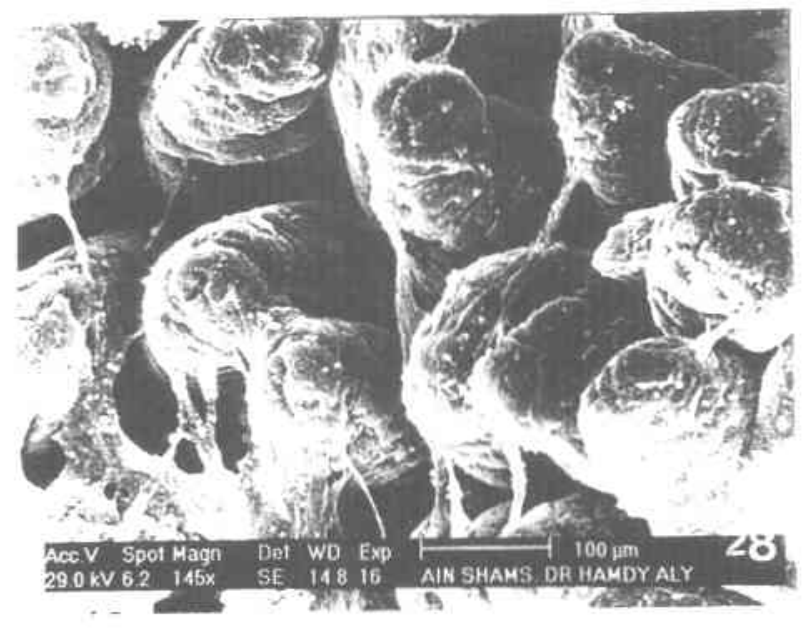

Fig. (28) : Scanning electron micrograph of the distal segment of jejunum of rabbits of group 11. Notice the filamentous mucus thrads.

(Scale bar $100 \mu$ ) 


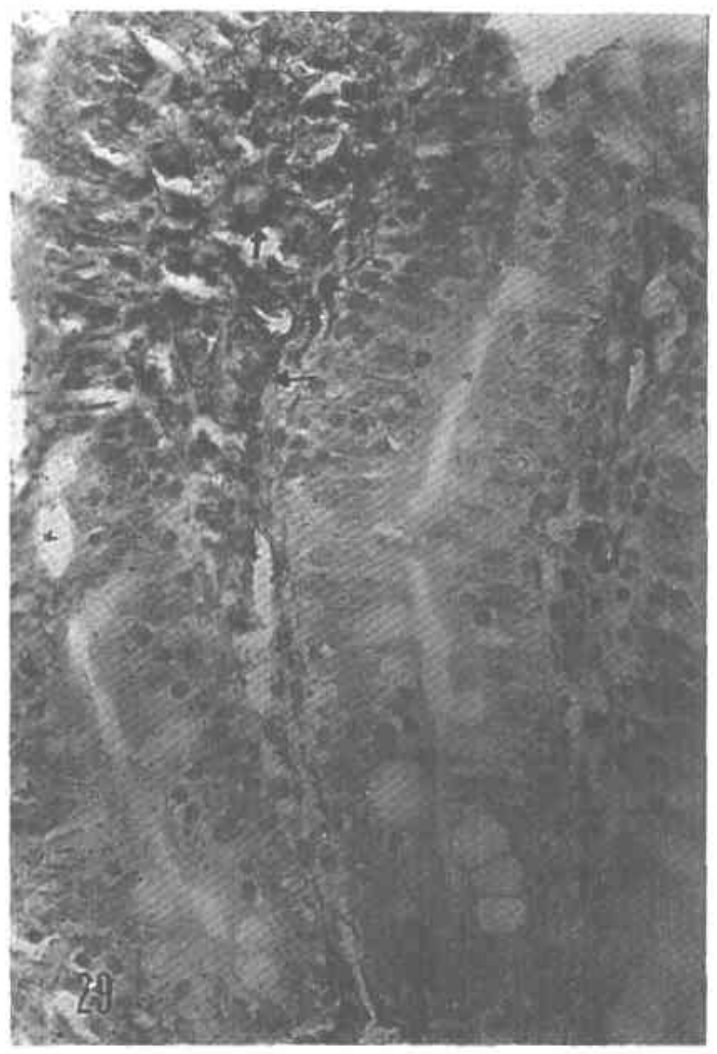

Fig. (29) : A photomicrograph of a section of distal segment. of jejunum of rabbits of group II. Notice the intensc nitric oxide synthase reaction in apical parts of villi $(\uparrow)$.

(NOS immuno-staining $\mathrm{x} 400$ ) 


\section{DISCUSSION}

The present study revealed that the intestine subjected to segmental ischemia reperfusion or continuous ischemia was dramatically alfected. Furthermore, it provided evidences that delayed morphological changes were not limited to the ischemic scgments but involved distal scgments as well.

The present work revealed that following ischemia reperfusion the general architecture of the villi was largely preserved. However, the mean height of the villi was significantly reduced. In continuous ischemia, there was exacerbation of mucosal injury. Most of the villi were denuded, atrophied with loss of their finger like shapes. Significant reduction in the mean height of the villus was further noticed. It is hypothesized that the height of the villi is the most reliable and carly detectable ischemic change. It could be considered as an excellent parameter for evaluating early ischemic changes (Puglisi et al., 1995). The present work showed that the changes in the height of the villi could be considered as one of the remarkable signs of the delayed morphological changes in both ischemia and ischemia-reperfusion. The significant shortening of the villi in continuous ischemia than in ischemia reperfusion would be expected to cause more reduction in the mucosal surface area (Vatistas et al., 1998).

On the other hand, in the ischemic segment the mean thickness of the villi in ischemia reperfusion was significantly increased, while during continuous ischemia the mean thickness of villi was significantly reduced when compared with the control or with the group subjected to ischemia reperfusion. The increased thickness of villi during ischemia reperfusion is most likely attributed to mucosal edema and acute accumulation of extracellular fluid rather than to the effects of diminished blood flow (Ostgaard and Reed, 1995; Rha et al., 2000). The reduction of thickness of villi encountered in the present study during continuous ischemia is probably due to the absence of edema. It is belicved that mucosal edema develops only on reperfusion (Puglisi et al., 1995).

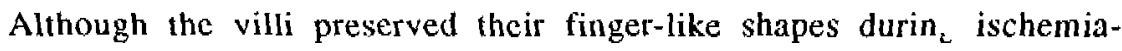
reperfusion, yet the typical brush border was ill-defined. The enterocyles were significantly reduced in height and their pattern of organization was distorted. Numcrous enterocytes were detached and lifted from the villus stroma. Similarly, during continuous ischemia the height of enterocytes was significantly reduced when compared to the control. However, it did not show significant varialion from the height of enterocytes in ischemia-reperfusion, Unlike ischemia-reperfusion, the enterocytes 
in continuous ischemia were frequently detached along the entire length of the villi. Moreover. the detached cells had condensed or pyknotic nuclei.

D Mlachment of enterocytes from the tips of the villi was the early characteristic k'alure of ischemic damage to the small intestine (Ikeda et al., 1998). The present work showed that detachment of enterocytes was also a prominent delayed fealure of ischemia-reperlusion. The reason for epithclial shedding is the appearance of membranc enclosed cytoplasmic blebs which arise at the base of the enterocytes and cause the detachment from the basement membrane (Ikeda et al., 1998). The condensation of nuclei and pyknosis are the characteristic morphological features of apoptosis (Puglisi et al., 1995). It has been proposed that the interaction between the extracellular matrix and detached cells plays a critical role in apoptosis (Frisch and Francis, 1994). Moreover, it was hypothesized that apoptosis might be due to increased plasma levels of histamine (Yoshida et al., 2000). Recently, oxidative stress was considered also as one of the causes of apoptosis (Jacob et al., 2003).

Scanning electron microscopic studies further revcaled that following ischemia reperfusion the villi were frequenlly fused together with ill defined boundaries and irregular orientation. The morphological alterations were noticed mainly in the apical parts of the villi as they appcared irregular and manifested multiple small knobs or werc partially detached. The surface of the villi showed sloughing of epithelial cells and ill-defined microvilli. Localizcd areas without surface villi were also encountered. On the other hand, during continuous ischemia, the apices of the villi werc complctely distorted and the jejunum exhibited wide areas of ulceration with complete loss of the surface epithclium and the microvilli. It was reported that superficial necrosis always started at the tips of villi in ischemia reperfusion (Chin et al., 2002). In the present work, it was evident that the degencrative changes were manifested in the apical parts of the villi in both models of ischemia performed. Schlichting et al. (1995) noticed shrinkage of the villi, mucosal ulceration, necrosis and complete loss of epithelial cell renewal in ischemia-reperfusion achieved by complete occlusion of the superior mesenteric artery. Occlusion of arcades followed by reperfusion was assumed to cause reduction of epithelial converge up to $23 \%$ (Gangadharan et al., 1995).

The sloughing of epithelial cells noticed in the present work might greatly hinder the absorption of nutrients produced by the digestive process. Moreover, the absence of microvilli might abolish their physiological function and reduce contact between intestinal surlace and the nutrients disturbing the absorption (Junqueira and Carneiro, 2003). The surface ulceration encountered in the present study following 
continuous ischemia might imply that the epithelial barrier integrity is impaired. The impairment is triggered by tissue hypoxia and the activation of the phagocytic system which might lead to macromolecular leakage and finally might lead to organ dysfunction (Sun et al., 2000).

In the present study, the core of the villi represented distinguishable changes in both models of ischemia. In ischemia reperfusion, the core manifested mononuclear cellular infiltration. amorphous eosinophilic material and agreggation of red blood cells. Less frequently, vacuolated areas were noticed. In addition, the reticular fibers were compressed and partially disrupted. In continuous ischemia. the core exhibited extensive hemorrhages and marked mononuclear cellular infiltration, while the reticular fibers were thin. short and fragmented.

The mononuclear cellular infiltration encountered in the present work might be a function of cytokine induced neutrophil chemoattractant which is elevated during ischemia or ischemia reperfusion playing an important role in neutrophil infiltration (Yagihashi et al., 1998). Leucocytic infiltration could be attributed also to increased vascular or mucosal permeability (Kanwar et al., 1998). The leucocytes were not only increased but were assumed to be adherent (Kalia et al., 2001). The present study clarified that the cellular infiltration during continuous ischemia was always accompanied by hemorrhage. It is believed that hemorthagic mucosal lesions produced during ischemia are duc to accumulation and activation of polymorphnuclear leucocytes in the lissucs and might predispose to sepsis (Rollwagen et al., 2000). Inhibition of neutrophil accumulation could attenuate hemorrhagic mucosal lesions (Schoenberg et al., 1995).

Immunohistochemical studies revealed that endothelial cells of blood vessels within the core of the villi of the control groups exhibited strong nitric oxide synthase reaction mainly in the apical parts of the villi and to lesser extent in the basal parts of the villi. The present study revealed that nitric oxide synthase reaction was weak in ischemia repertusion and occurred at intertupted wide intcrvals. In continuous ischemia the reaction was extremely weak and localized. The production of nitric oxide and its role during ischemia is still subjected to controvert ideas. The weak reduced nitric oxide synthase reactions encountered in the present work is suggestive of diminished nitric oxide production during ischemia. Microvascular impairments are gencrally noticed to be associated with reduction in nitric oxide production (Fruchterman et al., 1998). Inhibition of nitric oxide synthase might participate in intestinal apoptosis (Yoshida et al., 2000). Moreover. diminished 
nitric oxie synthase could be the cause of structural and functional alterations in the mitochondria (Madesh et al., 2000).

Activation of nitric oxide synthesis and production to achievc a cytoprotective role was only noticed if ischemia was proceeded with ischemic preconditioning (Valsov et al., 2002). Contrary to the results of the present work, Takada et al. (1998) noticed accelerated nitric oxide production in ischemia reperfusion and suggested that it participated in breakdown of intestinal mucosa, exerting a cytotoxic effect.

The intestinal scgments distal to ischemia are of special clinical importance. The morphological changes in such segments were not properly clarified. The present work illustrated that during ischemia reperfusion, the general architecture and the shape of villi in the distal segment were intact. The height of the villi did not exhibit significant variation from the control. On the other hand in continuous ischemia, the shape of the villi in the distal segments was also intact apart from slight broadening of the villus tips. The mean height of villi was significantly reduced. Such discrepancy in the height of villi might indicate that in ischemia-reperfusion the mucosal surface area is probably unattered and preserved in distal segments. However, it might be disturbed in continuous ischemia (Vatistas et al., 1998). Morphometeric analysis comparing the height of villi in distal segments of both models of ischemia performed with height of villi in the ischemic segments showed that the height of villi in distal segments was always higher.

During ischemia-reperfusion the mean thickness of villi in distal segments was significantly decreased than both the control and ischemic segments, while during continuous ischemia the mean thickness of villi in distal segments was significantly increased than both the control and ischemic segment. The decrease in thickness of villi in ischemia reperfusion indicates absence of edema in distal segments and its restriction to ischemic segments only (Puglisi et al., 1995). The increase in thickness of villi in continuous ischemia is suggestive of occurrence of edema in distal segments. Clinically, incisions are preferred, to be done in distal segments to ischemic site in order to make it in less cdematous area (Steen Voorde et al., 2003).

Scanning clectron microscopic examination revealed that the villi in distal segments of both ischemia and ischemia-reperfusion had preserved outlines, intact surface epithelium and microvilli. However, during ischemia-reperfusion goblet cells formed multiple aggregates. Moreover, in continuous ischemia the surface of villi 
manifested filamentous mucus threads. The intense mucus secretion provides protection and lubrication to intestinal segments potentially exposed to inflammation (Jacob et al., 2003).

Furthermore, the present study clarified that the core of villi in distal segments exhibited marked mononuclear cellular infiltration. It is belicved that during ischemia the inflammation is not restricted to the ischemic segment only or segments distal. It is postulated that ischemia favors the increase of microflora and the dissemination of different organisms even in the spleen. kidney and liver (Meddah et al,, 2001). The increase in microorganisms triggered an increase in the resident inflammatory cells within the gut wall and raised the possibility that under conditions of ischemic stress, pro-inflammatory mediators might also be activated by toxic factors in gut lumen (Harari et al., 2000).

In addition to the marked mononuclear cellular infiltration the present work revealed that the core of villi had cxtensive branching thickened network of reticular fibers particularly in the basal parts of the villi. Generally, the small diameter of the reticular fibers and their loose deposition create a flexible network in organs subjected to motility or changes in volume (Junqueira and Carneiro, 2003). The thickening and branching of relicular fibers noticed in the core of the villi might explain the decreased motility, contraction frequency and relaxation frequency noticed after ischemia and might clarify the occurrence of clinical ileus or transit ingest in distal segments (Malone and Kanaan, 2001).

The present study further clarified that the core of villi in the distal segments exhibited intensified nitric oxide synthase reaction particularly in the apical parts of the villi. The intense reaction is suggestive of increased nitric oxide production. Nitric oxide formed in the endothelial cells diffuses in the blood to exert its effects (Koslov et al., 2001). It is belicved that nitric oxide could probably provide protection to the distal bowel (Chan et al., 2002). Administration of nitric oxide donner FK 409 in ischemia-reperfusion significantly reduced leucocytes adhesion, macromolecular leakage and maintained villous blood flow and was of great value in reducing tissue damage (Kalia et al., 2001). The intense nitric oxide synthase reaction noticed in the present study might indicate that nitric oxide seems to be involved in bowel protection after ischemia, and could be of value in maintenance of the distal segments.

In conclusion. the present work clarified that persistent morphological and morphometric changes were encountered in the jejunal villi following ischemiareperfusion. These changes were more evident following continuous ischemia. The 
distal segments manifested few alterations that should be considered during clinical management of ischemia or ischemia-rcperfusion.

\section{SUMMARY}

The aim of the present work was to illustrate the delayed morphological and morphometeric changes following segmental ischemia and ischemia-reperfusion in the jcjunal villi of rabbits. Moreover, the present work aimed to investigate the changes that are likely to occur in intestinal scgments distal to ischemia. Rabbits were divided into two groups. In the first group the terminal blood vessels of the selected jejunal segments were occluded for sixty minutes with a vascular clamp followed by reperfusion. In the sccond group the terminal blood vessels of the selected jejunal segments were continuously ligated with polygalactin. Both the ischemic and distal segments were excised after 24 hours.

Following ischemia-reperfusion, the ischemic segment cxhibited significant decrease in height and significant increase in thickness of the villi. The enterocytes were disorganized and significantly reduced in height. The core of villi contained mononuclear cellular infiltration, cosinophilic material, aggregation of red blood cells and disrupted fragmented reticular fibers. Moreover, nitric oxide synthase reactions were weak. Scanning electron microscopic examination revealed distorted partially detached apices, sloughing of the epithelial cells of the villi and ill-defined microvilli. On the other hand, segments distal to ischemic ones, revealed non significant variation in height and significant reduction in thickness of the villi as compared to the control group. However, on comparing with the ischemic segment, the height of the villi was significanlly higher and the thickness was significantly reduced. The villi had intact brush border and regular arrangement of enterocytes, but their height was significantly reduced. The core of the villi manif'csted severe mononuclear cellular infiltration, thickened dense reticular fibers and strong nitric oxide synthase reactions. Scanning clectron microscopic st udies revealed irregular orientation of some villi. However, the surface epithelium was intact and cxhibited numerous microvilli. Aggregations of goblet cells were commonly noticed.

Following continuous ischemia, the ischemic scgment presented atrophied villi. The mean height and thickness of the villi were significantly reduced as compared to the control or to the group subjected to ischemia-reperfusion. The pattern of organization of enterocyles was lost and the cells were significantly reduced in height. The enterocytes were detached along the entire length of the villi and the detached cells 
showed condensed and pyknotic nuclei. The core of the villi exhibited hemorrhage, mononuclear cellular infiltration, complete disruption of the reticular fibers and extremely weak localized nitric oxide synthase reactions. Scanning electron microscopic examination showed areas of ulceration with complete loss of surface epithelium and microvilli. Regarding the distal segment, the villi showed significant decrease in height and significant increase in thickness as compared to the control. On comparing with the ischemic segment, the height and thickness of the villi of distal segments were significantly increased. Though the entcrocyles were not detached, they were significantly reduced in height and showed few condensed nuclei. The core exhibited marked mononuclear cellular infiltration, dense reticular fibers in the basal parts of the villi and strong nitric oxide synthase reactions. Scanning electron microscopic examination revealed characteristic filamentous mucus threads encroaching on the surface of the villi. It was concluded that persistent changes were noticed in jejunal villi following both models of ischemia. However, the changes were deletcrious in continuous ischemia. Distal segments revealed slight alterations particularly in the core of the villi.

\section{REFERENCES}

1. Chan, K.L... Hui, C.W.; Chan, K.W.; Fung, P.C.; Woj, Y.; Tipoe, G. and Tam, P.K. (2002) : Revisiting ischemia and reperfusion injury as a possible cause of necrotizing enterocolitis. Role of nitric oxide and super oxide dismutase. J. Pediatr. Surg.. $37(6): 828-8.34$.

2. Chin, A.C.; Singer, M.A.; Mihalov, M.; Abcarian, H.; Cintron, D.R.; Radha Krishnand; Dambar, A. and Owens, C.A. (2002) : Super selective mesenteric embolization with microcoils in a porcine model. Dis. Colon, Rectum., 45 (2) : $212-218$.

3. Frisch, S.M. and Francis, H. (1994) : Disruption of epithclial cell-matrix interactions induces apoptosis. J. cell, Biol., $124: 619$ - 626.

4. Fruchterman, T.M.; Spain, D.A.; Wilson, M.A.; Harris, P.D. : ud Garrison, R.N.. (1998) : Selective microvascular endothelial cell dyslunction in the small intestine following resuscitated hemorrhagic shock. Shock, 10 (6) : 417 - 422.

5. Gangadharan, S.P.; Wanger, R.J. and Cronenwe, J.L. (1995) : Effect of intravenous glycogen on intestinal viability after segmental mesenteric ischemia. $J$. Vasc. Surg. $21(6): 900-908$. 
6. Harari, Y.; Weisbrodot, N.W. and Moody, F.G. (2000) : lleal mucosal response to bacterial toxin challenge. J. Trauma, $49(2): 306-313$.

7. Ikeda, H.; Suzuki, Y.; Luzuki, M.; Koike, M.; Tamura, J.; Tong, .I.; Nomura, M. and Itoth, G. (1998) : Apoptosis is a major mode of cell death caused by ischemia and ischemia reperfusion injury to the rat intestinal epithelium. Gut., 42 (4) : 530 - 537.

8. Ito, K.; Ozasa, H.; Kojima, N.; Miuram, E.; Iwa, T.; Senoo, H. and Horikawa, S. (2003) : Pharmacological pre-conditioning protects lung injury induced by intestinal ischemia-reperfusion in rat. Shock, 19 (5) : 462 - 468.

9. Jacob, T.; Ascher, E.; Hingorani, A. and Kallakuri, S. (2003) : Glycine prevents the induction of apoptosis attributed to mesenteric ischemia reperfusion injury in rat model. J. Surg.. $134(3): 457+466$.

10. Junqueira, L.C. and Carneiro, J. (2003) : Basic histology Text and Atlas. 10 ed.. Lang Medical books Mc Craw - Hill.. 308 - 309.

11. Kalia, N.; Pockley, A.G.; Wood, R.F. and Brown, N.J. (2001) : Effects of FK409 on intestinal ischemia-reperfusion injury and ischemia induced changes in rat mucosal villus microcirculation. Transplantation. 72 (12) : 1875 - 1880.

12. Kanwar, S.; Hickey, M.J. and Kubes, P. (1998) : Post ischemic inflammation a role for mast cells in intestinc but not in skeletal muscle. Am. J. Physiol., 275 (2 pt 1$): 212-218$.

13. Kozlov, A.V.; Sobhian, B.; Costantino, G.; Nohl, N.; Redl, H. and Bahrami, S. (2001) : Experimental evidence suggesling that nitric oxide diffuses from tissues into blood but not from blood into lissues. Biochem-Biophys. Acta.. 1536 (2 -3) : 117 - 184.

14. Lock, G. (2001) : Acute intestinal ischemia. Best. Pract. Res. Clin. Gastroenterol., 15 (1): $83-98$.

15. Madesh, M.; Ramachandran, A.; Pulimood, A.; Vadranam, M. and Bala subramanian, K.A. (2000) : Attenuation of intestinal ischemia reperfusion injury with sodium nitro prusside; studies on mitochondria lunction and lipid changes. Bio. Chem. Biophys., 1500 (2) : 204 - 216.

16. Malone, E.D. and Kanaan, M.S. (2001) : Effects of intestinal ischemia on in vitro activity of adjacent jejunum samples obtaincd from ponies. Am. D. Vet. Res., 62 (12) : 1973 - 1978.

17. Meddah, A.T.; Leke, L.; Romond, M.B.; Grenier, E.; Cordonnier, C.; Pisbourg, B. and Canarelli, D.P. (2001) : The effect of mesenteric ischemia on ileal colonization. intestinal integrity and bacterial translocation in new born piglets. Pediatr. Surg. Int., 17 (7) : 515 - 520. 
18. Nakamura, N.; Hamade, N.; Murata, R.; Kobayashi, A.; Ishizake, N.; Taira, A. and Sakara, R. (2001) : Contribution of serotonin to liver injury following canine small intestinal ischemia and reperfusion. Surg. Res.. 99 (1) : 17 24.

19. Ostgaard, G. and Reed, R.K. (1995) : Interstitial fluid accumulation docs not influence oxygen uptake in the rabbit small intestinc. Acta. Anaesthesiol. Scand., $39(2): 167-173$.

20. Puglisi, R.N.; Whalen, T.V. and Doolin, E.J. (1995) : Computer analyzed histology of ischemic injury to the gut. J. Pediatr, Surg., 30 (6) : 839 - 844.

21. Rha, S.E.; Ha, H.K.; Lee, S.H.; Kim, J.H.; Kim, J.K.; Kim, P.N.; Lee, M.G. and Auh, Y.H. (2000) : C.T. and M.R. Imaging findings of bowel ischemia from various primary causes. Radiographic, $20(1): 29-42$.

22. Rollwagen, F.M.; Li, Y.Y.; Pacheco, N.D.; Dick, E.J. and Kang, Y.H. (2000) : Micro-vascular effects of oral interlcukin 6 on ischemia-reperfusion in the murine small intestine. Am. J. Pathol., 156 (4) : $1177-1182$.

23. Schlichting, E.; Grotmol, T.; Kahler, H.; Naess, O.; Steinbakk, M. and Lyberg, T. (1995) : Alterations in mucosal morphology and permeability but no bacterial or endotoxin translocation takes place after intestinal ischemia and early reperfusion in pig. Shock, $3(2): 116-124$.

24. Schoenberg, M.H.; Poch, B.; Moch, D.: Marzinzig, M.; Marzin Zig, E.; Matt feldt, T.; Gruber, H. and Begger, H.G. (1995) : Effect of acadesine treatment on post ischemic damage to the small intcstine. Am. J. Physiol., 269 (5 pt 2) : 1752 - 1759.

25. Steen Voorde, P.; Schaardenburgh, P. and Viersma, D.H. (2003) : Enterolith ileus as a complication of jejunal diverticulosis two case reports and a review of the litcrature. Dig. Surg. 20 (1) : $57-60$.

26. Sun, Z.; Wang, X.; Deng, X.; Borjession, A.; Wallen, R.; Hallberg, E. and Andreseon, R. (2000) : Phagocytic and intestinal endothelial and epithelial barrier function during the carly stage of small intestinal ischemia and reperfusion. Shock, 13 (3) : $204-216$.

27. Takada, K.; Yamashita, K.; Sakwrai-Yamashita, Y.; Shirmatsu, K.; Hamada, Y.; Hioki, K. and Taniyama, K. (1998) : Participation of nitric oxide in the mucosal injury of rat induced by ischemia reperfusion. J. Pharmacol. Exp. Therp.. 287 (1) : 403 - 407.

28. Takeyoshi, I.; Zhang, S.; Nakamura, K.; Ikoma, A.; Zhu, Y.; Starz, T.E. and Todo, S. (1996) : Effect of ischemia on the canine large bowcl. A comparison with the small intestine. J. Surg. Res.. 62 (1):41-48. 
29. Valsov, T.D.; Smirnov, D.A. and Nutfullena, G.M. (2002) : Preconditioning of the small intestine to ischemia in rats. Neurosci. Behav. Physiol., 32 (4) : 449 453.

30. Vatistas, N.J.; Snyder, D.R.; Niero, D,; Hildebrand, S.V.; Woliner, M.D.; Harmon, F.A.; Barry, S.D. and Drake, G. (1998) : Morphologic changes and xanthine oxidase activity in the equine jejunum during low flow ischemia and reperfusion. Am. J. Vcu. Res, 59 (6) : $772-776$.

31. Yagihashi, A.; Tsuruma, T.; Tarumi, K.; Kameshima, T.; Yajima, T.; Yanai, Y.; Watanake, N. and Hirata, K. (1998) : Prevention of small intestinal ischemia-reperfusion injury in rat by anticytokine induced neutrophil chemoattraclant monoclonal antibody. J. Surg. Res., 78 (2) : $92-96$.

32. Yoshida, T.; Iwakiri, R.; Noda, T.; Okamoto, K.; Kojima, M.; Fukuyama, K. and Fujimoto, K. (2000) : Histaminergic effect on apoptosis of rat small intestinial mucosa after ischemia-reperfusion. Dig. Dis. Sci., 45 (6) : $1138-1144$. 


\section{المخص العربى}

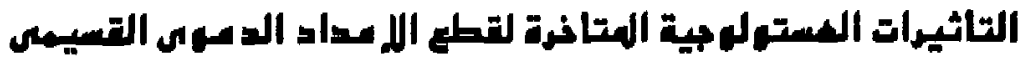

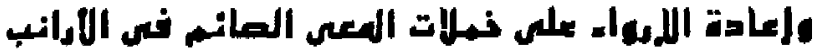 \\ شهيرة يـوسن.}

قسم التثريح - كلية الطب - جامعة عين شعس

استهـفت هذه الدرامية توضيح التفيرات الثبكية والتياسية فى أمعاء الأرانب

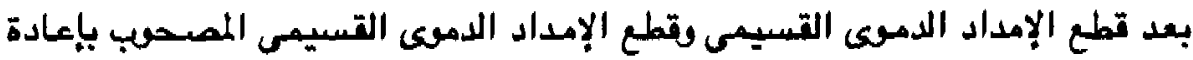

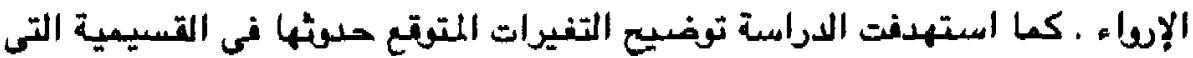

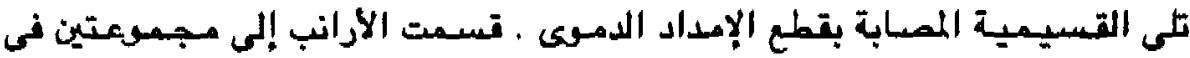

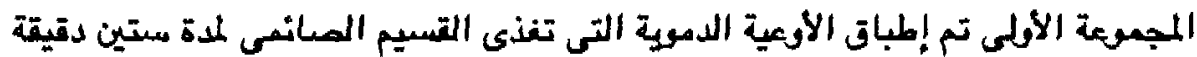

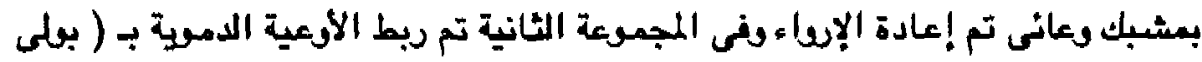

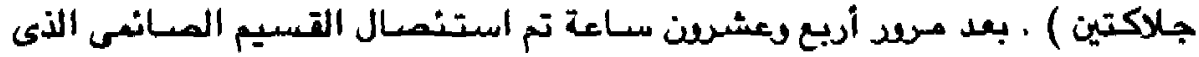
تعرض لقطع الإمداد الدموى بالقسيم التالى له .

قد تبين أن تطع الإمداد الدهوى وإعادة الإبراء قد تسبب فى قصر نسبى فى طول

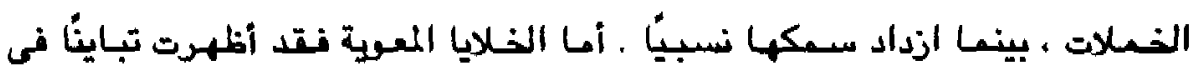
ترامسها وقصر نسبع طرلها ـ واحتوى تلب الخملات على تجمع خلايا أحادية النوايا

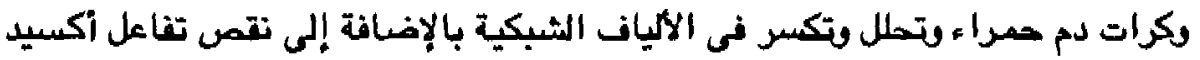

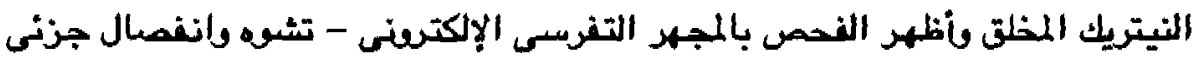

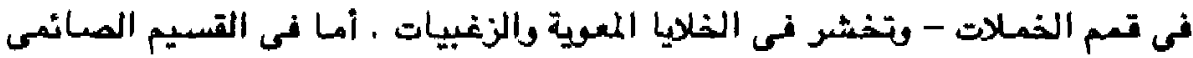

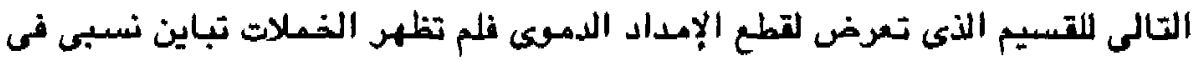

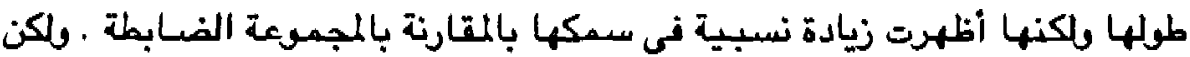

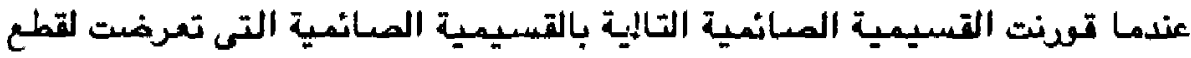

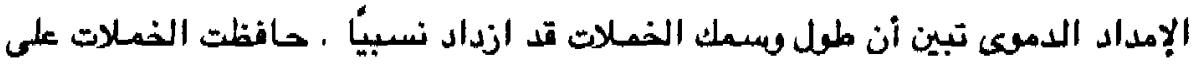




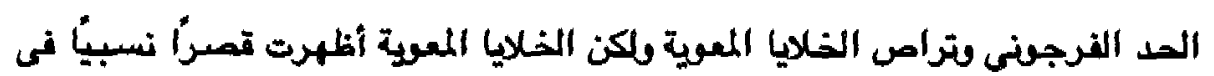

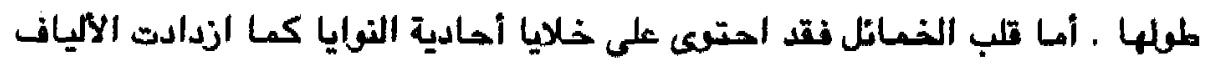

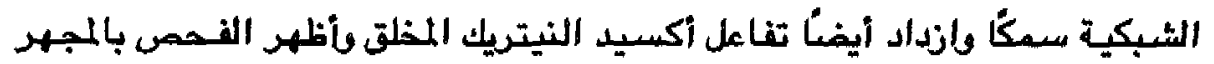

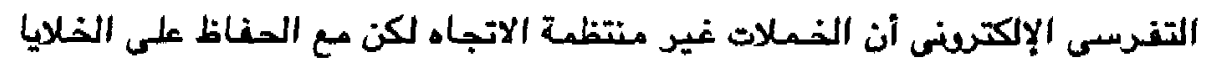

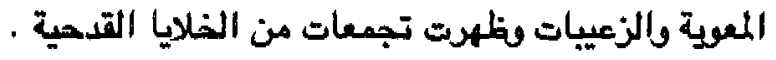

أما القسيعية المانمية المعرخسة لقطع الإمـداد الدمقي المستمر فقد اظلهرت

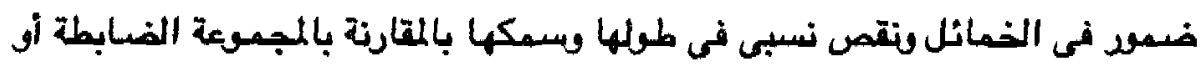

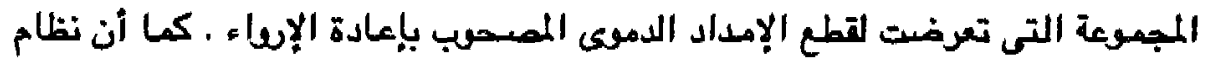

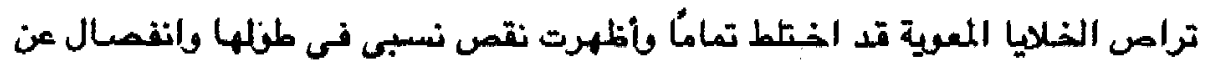

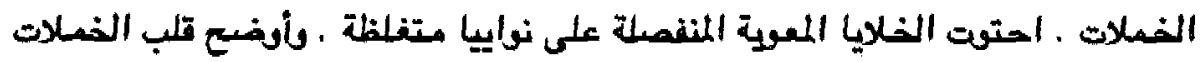

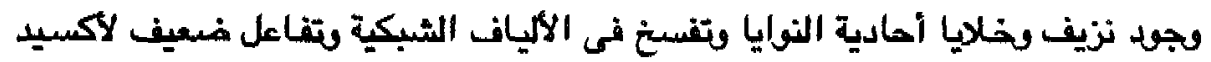

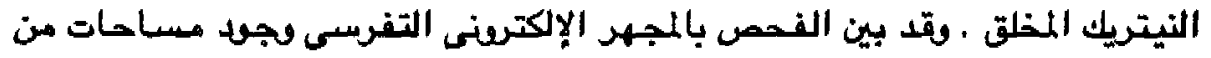

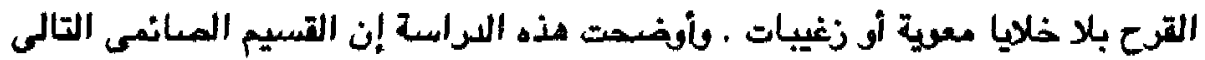

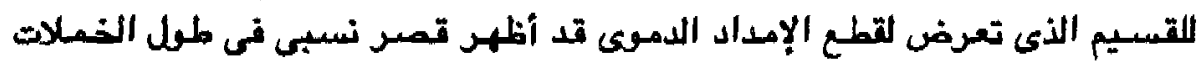

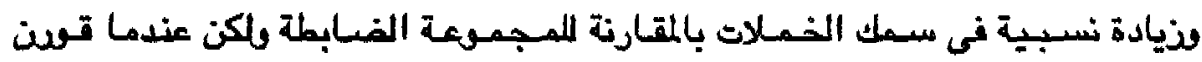

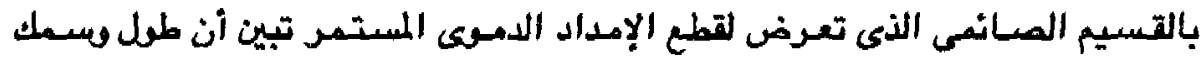

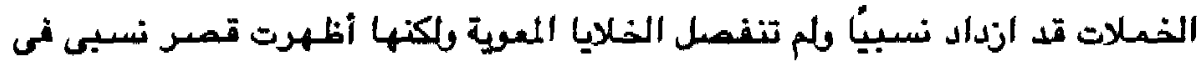

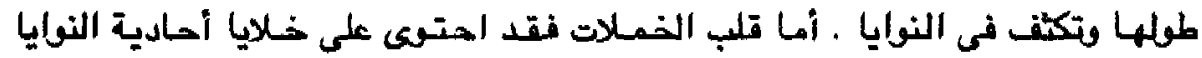

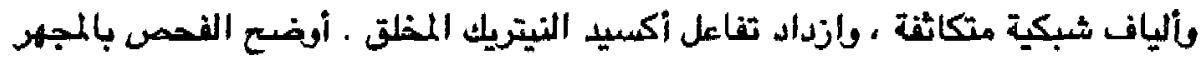

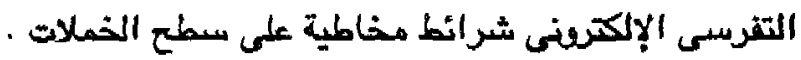

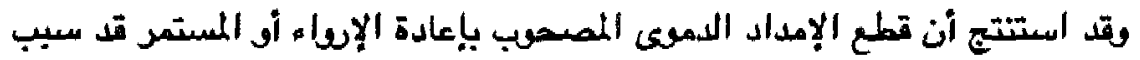

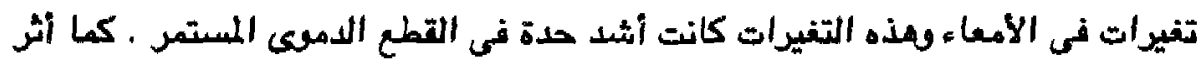

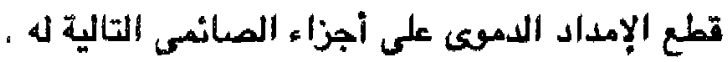

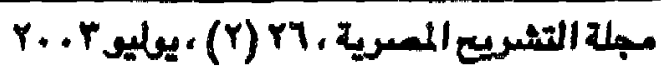

